\title{
Plant Alkaloids Inhibit Membrane Fusion Mediated by Calcium and Fragments of MERS-CoV and SARS-CoV/SARS-CoV-2 Fusion Peptides
}

\author{
Egor V. Shekunov ${ }^{1}\left(\mathbb{D}\right.$, Svetlana S. Efimova ${ }^{1, *(\mathbb{D})}$, Natalia M. Yudintceva ${ }^{1}$, Anna A. Muryleva ${ }^{2}$, \\ Vladimir V. Zarubaev ${ }^{2}$, Alexander V. Slita ${ }^{2}$ (D) and Olga S. Ostroumova ${ }^{1}$ \\ 1 Institute of Cytology of Russian Academy of Sciences, Tikhoretsky 4, 194064 Saint Petersburg, Russia; \\ e.shekunov@alumni.nsu.ru (E.V.S.); yudintceva@incras.ru (N.M.Y.); ostroumova@incras.ru (O.S.O.) \\ 2 Saint-Petersburg Pasteur Institute of Epidemiology and Microbiology, Mira 14, \\ 197101 Saint Petersburg, Russia; anna.murka09099@mail.ru (A.A.M.); zarubaev@gmail.com (V.V.Z.); \\ a_slita@yahoo.com (A.V.S.) \\ * Correspondence: efimova@incras.ru
}

\section{check for} updates

Citation: Shekunov, E.V.; Efimova, S.S.; Yudintceva, N.M.; Muryleva, A.A.; Zarubaev, V.V.; Slita, A.V.; Ostroumova, O.S. Plant Alkaloids Inhibit Membrane Fusion Mediated by Calcium and Fragments of MERS-CoV and SARS-CoV/ SARS-CoV-2 Fusion Peptides. Biomedicines 2021, 9, 1434. https:// doi.org/10.3390/biomedicines9101434

Academic Editor: Pavel B. Drašar

Received: 26 August 2021

Accepted: 7 October 2021

Published: 10 October 2021

Publisher's Note: MDPI stays neutral with regard to jurisdictional claims in published maps and institutional affiliations.

Copyright: (c) 2021 by the authors. Licensee MDPI, Basel, Switzerland. This article is an open access article distributed under the terms and conditions of the Creative Commons Attribution (CC BY) license (https:// creativecommons.org/licenses/by/ $4.0 /)$.

\begin{abstract}
To rationalize the antiviral actions of plant alkaloids, the ability of 20 compounds to inhibit calcium-mediated fusion of lipid vesicles composed of phosphatidylglycerol and cholesterol was investigated using the calcein release assay and dynamic light scattering. Piperine, tabersonine, hordenine, lupinine, quinine, and 3-isobutyl-1-methylxanthine demonstrated the most potent effects (inhibition index greater than 50\%). The introduction of phosphatidylcholine into the phosphatidylglycerol/cholesterol mixture led to significant changes in quinine, hordenine, and 3-isobutyl-1methylxanthine efficiency. Comparison of the fusion inhibitory ability of the tested alkaloids, and the results of the measurements of alkaloid-induced alterations in the physical properties of model membranes indicated a potent relationship between a decrease in the cooperativity of the phase transition of lipids and the ability of alkaloids to prevent calcium-mediated vesicle fusion. In order to use this knowledge to combat the novel coronavirus pandemic, the ability of the most effective compounds to suppress membrane fusion induced by fragments of MERS-CoV and SARS-CoV/SARS-CoV-2 fusion peptides was studied using the calcein release assay and confocal fluorescence microscopy. Piperine was shown to inhibit vesicle fusion mediated by both coronavirus peptides. Moreover, piperine was shown to significantly reduce the titer of SARS-CoV2 progeny in vitro in Vero cells when used in non-toxic concentrations.
\end{abstract}

Keywords: alkaloids; membrane fusion; viral fusion inhibitor; antiviral therapy; COVID-19

\section{Introduction}

More than a third of FDA-approved compounds are natural substances of plant origins or their derivatives [1]. Plant compounds play a major role in the pharmaceutical industry due to their safety and relative cheapness [2-4]. Alkaloids are a wide class of nitrogen-containing compounds with basic properties numbering more than 8000 representatives [5]. Alkaloids demonstrate multiple biological activities, including antiviral [6], antibacterial [7], and antifungal actions [8]. Alkaloids were shown to be effective against Retroviridae [9-12], Togaviridae [13], Herpesviridae [14,15], Flaviviridae [16-19], Filoviridae [20], and Orthomyxoviridae [21,22]. Due to the global epidemiological situation, the ability of alkaloids to effectively fight viruses of the Coronaviridae family, including SARS-CoV-2, is of particular interest [23-27]. The use of alkaloids against COVID-19 were recently explored in clinical practices [28]. The literature indicates that the mechanisms of the antiviral activities of alkaloids are pleiotropic. For example, suppression of HIV by alkaloids, fagaronine, nitidine, columbamine, berberine, palmatine, and coraline is mediated by the inhibition of reverse transcriptase [29], while antiviral activity against the hepatitis B virus is related to 
the reduction of the activity of the p38 MAPK protein [30]. The extensive antiviral activity of alkaloids might suggest a more general and fundamental mechanism of their activity. Many viruses (influenza virus, HIV, SARS-CoV-2, Ebola virus, Zika virus, etc.), against which alkaloids are effective, are enveloped, i.e., they contain a lipid membrane [31]. The fusion of viral and cell membranes is a necessary stage for the viral development cycle, and blocking this stage is an effective therapeutic strategy [32]. Currently, there are several works devoted to the inhibition of viral fusion through alkaloid-peptide interactions $[33,34]$. It was revealed that alkaloids can inhibit viral fusion through interactions with cellular factors [35] and viral proteins [17,18,25,26,36]. However, the contribution of the lipid matrix and its biophysical properties to the fusion remains underestimated [37,38]. Research devoted to the study of fusion inhibitors, targeting the physical properties of viral and cell membranes, is still not sufficient [39].

Model lipid bilayers are usually used to rationalize and better understand the membrane fusion process [40-42]. Namely, the use of systems with specified physical parameters provides an accurate interpretation of the results and make it possible to reveal the molecular basis of the studied processes [42-44].

The aim of this work was to determine whether the antiviral activity of alkaloids is related to the ability to inhibit the fusion of the viral and cell membranes. The ability of 20 structurally different alkaloids to inhibit the calcium-induced fusion of lipid vesicles was evaluated, and the dependence of the alkaloid inhibitory activity on the lipid composition of fusing liposomes was studied. In order to demonstrate the relationship between changes in the physical properties of the lipid matrix and the suppression of membrane fusion under the action of alkaloids, the alkaloid-induced changes in the transmembrane distribution of lateral pressure and electrostatic potential were also assessed. To show that the data obtained could have direct implications for clinical practices, in terms of using plant alkaloids as fusion inhibitors, the alkaloid ability to inhibit lipid vesicle fusion triggered by crucial fragments of MERS-CoV and SARS-CoV/SARS-CoV-2 fusion peptides was additionally tested. The most effective compound, piperine, was also evaluated for in vitro antiviral activity against SARS-CoV-2 for Vero cells.

\section{Materials and Methods}

\subsection{Materials}

All chemicals used were of reagent grade. Synthetic 1,2-dioleoyl-sn-glycero-3-phospho(1'-rac-glycerol) (DOPG), 1,2-dioleoyl-sn-glycero-3-phosphocholine (DOPC), 1-palmitoyl2-oleoyl-sn-glycero-3-phosphocholine (POPC), sphingomyelin (Brain, Porcine) (SM), 1,2dipalmitoyl-sn-glycero-3-phospho-(1'-rac-glycerol) (DPPG), cholesterol (CHOL), and 1,2dipalmitoyl-sn-glycero-3-phosphoethanolamine-N-(lissamine rhodamine B sulfonyl) (RhDPPE) were obtained from Avanti ${ }^{\circledR}$ Polar Lipids. Nonactin, $\mathrm{KCl}, \mathrm{CaCl}_{2}, \mathrm{PEG}-8000$, calcein, Triton X-100, Sephadex G-50, HEPES, DMSO, phosphate buffer solution (PBS), sorbitol, and alkaloids, atropine, (-)-lupinine, $(-)$-cotinine, berberine chloride, quinine, melatonin, caffeine, 1,7-dimethylxanthine, 3,9-dimethylxanthine, theophylline, 3-isobutyl-1methylxanthine, 7-( $\beta$-hydroxyethyl) theophylline, pentoxifylline, hordenine, $( \pm)$-synephrine, colchicine, capsaicin, dihydrocapsaicin, and tabersonine, were purchased from SigmaAldrich Company Ltd. (Gillingham, UK). The chemical structures of the tested alkaloids are presented in Figure S1 (Supplementary Materials).

DMEM and DMEM/F12 culture mediums, fetal bovine serum (FBS), trypsin solution, and Dulbecco's phosphate buffer solution (DPBS) were purchased from Gibco ${ }^{\mathrm{TM}}$ (Life Technologies, Paisley, Scotland).

The modeling fusion peptides, FP-SARS-CoV-2 (RSFIEDLLFNKVT) and FP-MERS$\mathrm{CoV}$ (RSAIEDLLFDKVT), were synthesized by the IQ Chemical LLC (Saint-Petersburg, Russia). The purity of peptides was $\geq 98 \%$. 


\subsection{Calcein Leakage Assay}

The choice of membrane-forming lipids is related to the enrichment of the viral lipid envelope with negatively charged and neutral glycerophospholipids, CHOL, and SM [45-47]. Small unilamellar vesicles were prepared from the mixtures of DOPG/CHOL (80/20 $\mathrm{mol} \%)$, DOPC/DOPG/CHOL (40/40/20 mol\%), and POPC/SM/CHOL (60/20/20 $\mathrm{mol} \%$ ) by extrusion. The resulting liposome suspension contained $3 \mathrm{mM}$ lipid. Lipid stock in chloroform was dried under a gentle stream of nitrogen. Dry lipid film was hydrated by a buffer ( $35 \mathrm{mM}$ calcein, $10 \mathrm{mM}$ HEPES, pH 7.4). The suspension was subjected to five freeze-thaw cycles and then passed through a $100 \mathrm{~nm}$ nuclepore polycarbonate membrane for 13 times. The calcein that was not entrapped in the vesicles was removed by gel filtration with a Sephadex G-50 column to replace the buffer outside the liposomes with calcein-free solution ( $0.15 \mathrm{M} \mathrm{NaCl}, 10 \mathrm{mM}$ HEPES, pH 7.4). Calcein inside the vesicles fluorescence very poorly, because of strong self-quenching at millimolar concentrations, while the fluorescence of disengaged calcein in the surrounding media is due to liposome fusion [41].

Here, $\mathrm{CaCl}_{2}$ and PEG-8000 were used as widely recognized fusion inducers [48-51]. The results of adding the different concentrations of $\mathrm{CaCl}_{2}$ into aqueous solutions, bathing calcein-loaded DOPG/CHOL (80/20 mol\%) and DOPC/DOPG/CHOL (40/40/20 mol\%) liposomes, are shown in Figure S2a,b (Supplementary Materials), respectively. Moreover, 20 and $40 \mathrm{mM} \mathrm{CaCl}_{2}$ was used to induce the fusion of DOPG/CHOL and DOPC/DOPG/CHOL liposomes, respectively.

The structure/function study performed by [49] showed that the fragment of MERSCoV spike protein S2 subunit (RSARSAIEDLLFDKV), which is highly conserved throughout the coronavirus family, induces the dipalmitoylphosphatidylcholine/SM/CHOL liposome syncytium formation, and the IEDLLF core sequence has a key role in membrane perturbation. A shorter $\alpha$-helical fragment of MERS-CoV fusion peptide (RSAIEDLLFDKVT) and the homologous highly conserved fragment of SARS-CoV/SARS-CoV-2 fusion peptides (RSFIEDLLFNKVT) [52] were chosen to mimic viral associated fusion. The chosen peptides were further referred to FP-MERS-CoV and FP-SARS-CoV-2, respectively. FP-SARS-CoV-2 and FP-MERS-CoV were added to POPC/SM/CHOL vesicles $(60 / 20 / 20 \mathrm{~mol} \%)$ to induce membrane fusion. The results of adding the different concentrations of peptides into aqueous solutions, bathing calcein-loaded POPC/SM/CHOL vesicles, are shown in Figure S2c,d (Supplementary Materials). Moreover, $50 \mu \mathrm{M}$ FP-SARS-CoV-2 and $200 \mu \mathrm{M}$ FP-MERS-CoV were used to induce liposome fusion to test the inhibitory action of alkaloids.

To test the fusion inhibitory action of alkaloids, a fusion inducer (calcium or modeling fusion peptides at the appropriate concentrations) was added to liposomes, pre-incubated with $400 \mu \mathrm{M}$ of alkaloids (except for $40 \mu \mathrm{M}$ of tabersonine). Since tabersonine at a concentration of $400 \mu \mathrm{M}$ completely inhibited the calcium-mediated fusion of both DOPG/CHOL and DOPC/DOPG/CHOL vesicles, in order to understand whether its inhibitory effect depended on the lipid composition of liposomes, we reduced its concentration by 10-fold. Both concentrations of tabersonine $(40$ and $400 \mu \mathrm{M})$ were used to test its inhibitory action on the FP-SARS-CoV-2 and FP-MERS-CoV mediated fusion.

We found that the osmotic pressure gradient resulting from the addition of a fusion inducer or an inhibitor did not affect the leakage of calcein from liposomes (data not shown).

The degree of calcein release was determined using a Fluorat-02-Panorama spectrofluorometer (Lumex, Saint-Petersburg, Russia). The excitation wavelength was $490 \mathrm{~nm}$ and the emission wavelength was $520 \mathrm{~nm}$. Triton X-100 was added to a final concentration of $1 \%$ to each sample in order to completely disrupt liposomes, and the intensity after releasing the total amount of calcein from liposomes was measured. 
To describe the fusion of the liposomal membranes, the relative fluorescence of leaked calcein $(R F, \%)$ was calculated using the following formula:

$$
R F=\frac{I-I_{0}}{I_{\max } / 0.9-I_{0}} \cdot 100 \%,
$$

where $I$ and $I_{0}$ were the calcein fluorescence intensities in the sample, in the presence and absence of the fusion inducer/inhibitor, respectively, and $I_{\max }$ was the maximum fluorescence of the sample after lysis of liposomes by Triton X-100. Factor of 0.9 was introduced to calculate the dilution of the sample by Triton X-100.

The inhibition index (II) was calculated to characterize the relative efficiency of tested alkaloids to inhibit the fusion of liposomes compared to the action of the fusion inducer alone on the same liposome preparation:

$$
I I=\frac{R F_{U}-R F_{S}}{R F_{U}} \cdot 100 \%,
$$

where $R F_{U}$ and $R F_{S}$ were the maximum relative fluorescence of the leaked calcein at the vesicle fusion induced by the calcium or modeling fusion peptides in the absence $\left(R F_{U}, U=\mathrm{Ca}^{2+} / F P-M E R S-C o V / F P-S A R S-C o V-2\right)$ and presence of alkaloids $\left(R F_{S}\right)$, respectively. The estimation of $R F_{S}$ was made, taking into account the intrinsic effect of alkaloids (the calcein leakage due to the potent lipid disordering action of alkaloid alone, $R F_{A}$ ). Figure S3 and Table S1 (Supplementary Materials) present the kinetics and maximum values of $R F_{A}$ at the addition of different alkaloids into aqueous solutions, bathing calceinloaded DOPG/CHOL (80/20 mol\%) (Figure S3a), DOPC/DOPG/CHOL (40/40/20 mol\%) (Figure S3b), and POPC/SM/CHOL (60/20/20 mol\%) vesicles (Figure S3c). Time dependences of calcein leakage were fitted with two-exponential functions with characteristic times, $t_{1}$ and $t_{2}$, related to the fast and slow components of the release process.

\subsection{Confocal Fluorescence Microscopy}

The visualization of changes in the morphological features and behavior of vesicles in the suspension under the action of fusion inducers was performed by marking the liposome membranes by the fluorescent labeled lipid, Rh-DPPE. Giant unilamellar vesicles were prepared from the mixture of POPC/SM/CHOL $(60 / 20 / 20 \mathrm{~mol} \%)$ and $1 \mathrm{~mol} \%$ of fluorescent lipid probe Rh-DPPE by the electroformation method (standard protocol, $3 \mathrm{~V}$, $10 \mathrm{~Hz}, 1 \mathrm{~h}, 25^{\circ} \mathrm{C}$ ) using Nanion Vesicle Prep Pro (Munich, Germany). The resulting liposome suspension contained $1 \mathrm{mM}$ lipid in $0.5 \mathrm{M}$ sorbitol solution. The measurements of the liposome fusion were added; $10 \%$ of PEG-8000, $50 \mu \mathrm{M}$ of FP-SARS-CoV-2, and $200 \mu \mathrm{M}$ of MERS-CoV were used to induce membrane fusion and were incubated for 1-2 $\mathrm{min}$ at room temperature $\left(25 \pm 1^{\circ} \mathrm{C}\right)$. Vesicles were imaged through an oil immersion objective $(65 \times / 1.4 \mathrm{HCX}$ PL) using an Olympus (Hamburg, Germany). A helium-neon laser with a wavelength of $561 \mathrm{~nm}$ was used to excite Rh-DPPE. The temperature during observation was controlled by air heating/cooling in a thermally insulated camera.

\subsection{Dynamic Light Scattering}

Small unilamellar vesicles composed of DOPG/CHOL (80/20 mol\%) and POPC/SM/ CHOL $(60 / 20 / 20 \mathrm{~mol} \%)$ were prepared by the extrusion and were treated with $400 \mu \mathrm{M}$ of cotinine, melatonin, 3-isobutyl-1-methylxanthine, lupinine, piperine, hordenine, and 40 or $400 \mu \mathrm{M}$ of tabersonine for $30 \mathrm{~min}$ before the addition of $20 \mathrm{mM} \mathrm{CaCl}_{2}, 50 \mu \mathrm{M}$ FPSARS-CoV-2, and $200 \mu \mathrm{M}$ MERS-CoV solution. Three different control samples were used: unmodified liposomes and vesicles incubated with fusion inducer, and the inhibitor alone. We found that the addition of alkaloid alone into the liposome suspension did not result in a noticeable alteration in vesicle size (data not shown). The hydrodynamic diameter $(d, \mathrm{~nm})$ and zeta-potential $(\zeta, \mathrm{mV})$ were determined on a Malvern Zetasizer Nano ZS 90 (Malvern Instruments Ltd., Malvern, United Kingdom) by gradual titration of liposome suspension in PBS at $25^{\circ} \mathrm{C}$. 


\subsection{Membrane Boundary Potential Measurements}

Virtually solvent-free planar lipid bilayers were prepared using a monolayer-opposition technique [53] on a 50- $\mu \mathrm{m}$ diameter aperture in a 10- $\mathrm{m}$ thick Teflon film separating the two compartments of the Teflon chamber. The steady-state conductance of $\mathrm{K}^{+}$-nonactin was modulated via the two-sided addition of the colchicine, cotinine, 1,7-dimethylxanthine, capsaicin, synephrine, 3-isobutyl-1-methylxanthine, lupinine, piperine, tabersonine, and hordenine from different $\mathrm{mM}$ stock solutions in ethanol or methanol to the membranebathing solution $(0.1 \mathrm{M} \mathrm{KCl}, \mathrm{pH} 7.4)$ to obtain a final concentration ranging from $5 \mu \mathrm{M}$ to $1 \mathrm{mM}$. The aperture was pretreated with hexadecane. Lipid bilayers were made from DOPG/CHOL $(80 / 20 \mathrm{~mol} \%)$. The conductance of the lipid bilayers was determined by measuring membrane conductance $(G)$ at a constant transmembrane voltage $(V=50 \mathrm{mV})$. In the subsequent calculations, the membrane conductance was assumed to be related to the membrane boundary potential $\left(\varphi_{b}\right)$, the potential drop between the aqueous solution and the membrane hydrophobic core, by the Boltzmann distribution [54]:

$$
G \sim \xi \cdot C \exp \left(-\frac{z e \phi_{b}}{k T}\right)
$$

where $\xi$ is the ion mobility, $z e$ is the ion charge, $k$ is the Boltzmann constant, and $T$ is the absolute temperature.

$\mathrm{Ag} / \mathrm{AgCl}$ electrodes with $1.5 \%$ agarose $/ 2 \mathrm{M} \mathrm{KCl}$ bridges were used to apply $V$ and measure $G$.

The current was measured using an Axopatch 200B amplifier (Molecular Devices, LLC, Orleans Drive, Sunnyvale, CA, USA) in the voltage clamp mode. Data were digitized using a Digidata 1440A and analyzed using pClamp 10.0 (Molecular Devices, LLC, Orleans Drive, Sunnyvale, CA, USA) and Origin 8.0 (OriginLab Corporation, Northampton, MA, USA). Data were acquired at a sampling frequency of $5 \mathrm{kHz}$ using low-pass filtering at $200 \mathrm{~Hz}$.

All experiments were performed at room temperature $\left(25^{\circ} \mathrm{C}\right)$.

\subsection{Differential Scanning Microcalorimetry}

Differential scanning microcalorimetry experiments were performed by a $\mu$ DSC 7EVO (Setaram, Caluire-et-Cuire, France). Giant unilamellar vesicles were prepared from a mixture of DPPG/CHOL ( $90 / 10 \mathrm{~mol} \%$ ) by the electroformation method (standard protocol, $\left.3 \mathrm{~V}, 10 \mathrm{~Hz}, 1 \mathrm{~h}, 55^{\circ} \mathrm{C}\right)$. The liposome suspension contained $3 \mathrm{mM}$ lipid and was buffered by $5 \mathrm{mM}$ HEPES at $\mathrm{pH}$ 7.4. The tested alkaloids (colchicine, cotinine, 1,7-dimethylxanthine, capsaicin, synephrine, 3-isobutyl-1-methylxanthine, lupinine, piperine, and hordenine) were added to aliquots to obtain a final concentration up to $400 \mu \mathrm{M}$ of alkaloids (except for $40 \mu \mathrm{M}$ of tabersonine). The liposomal suspension was heated at a constant rate of $0.2 \mathrm{C} \cdot \mathrm{min}^{-1}$. The reversibility of the thermal transitions was assessed by reheating the sample immediately after the cooling step from the previous scan. The temperature dependence of the excess heat capacity was analyzed using Calisto Processing (Setaram, Caluire-et-Cuire, France). The peaks on the thermograms were characterized by the maximum temperatures of the main phase transition $\left(T_{m}\right)$ of DPPG/CHOL mixture and the half-width of the main peak $\left(T_{1 / 2}\right)$ indicating the size of the lipid cooperative unit.

\subsection{In Vitro Antiviral Activity Assessment}

To analyze the antiviral activity of piperine, monkey kidney epithelial cells, Vero (ATCC CCL81) were grown in culture vials (Nunc, Roskilde, Denmark) in DMEM culture medium supplemented with $10 \%$ FBS. The cell concentration was adjusted to $5 \times 10^{5}$ cells $/ \mathrm{mL}$, and cells were seeded into 96 -well culture plates $(0.1 \mathrm{~mL}$ per well). The plates were incubated for $24 \mathrm{~h}$ at $37^{\circ} \mathrm{C}$ in an atmosphere of $5 \% \mathrm{CO}_{2}$. Piperine was dissolved in DMSO, and then two-fold serial dilutions of 200 to $1.56 \mu \mathrm{g} / \mathrm{mL}$ in serum-free DMEM/F12 nutrient medium were prepared. Afterwards, $100 \mu \mathrm{L} /$ well of each dilution of piperine was added to Vero cells and incubated for $1 \mathrm{~h}$ at $37^{\circ} \mathrm{C}$ in a $5 \% \mathrm{CO}_{2}$ atmosphere. Serum-free 
DMEM/F12 medium was added to control wells instead of piperine. Aliquots of SARSCoV-2 $\left(10^{3} \mathrm{TCID} 50 / \mathrm{mL}\right)$ (isolate 17612) were mixed 1:1 with dilutions of piperine and incubated for $1 \mathrm{~h}$ at $37^{\circ} \mathrm{C}$. After $1 \mathrm{~h}$ incubation, piperine was removed from the plates, $100 \mu \mathrm{L} /$ well of the SARS-CoV2/piperine mixture was added to the corresponding wells and incubated for $1 \mathrm{~h}$ at $37{ }^{\circ} \mathrm{C}$ in a $5 \% \mathrm{CO}_{2}$ atmosphere, the virus-containing medium was added to the wells of the viral control, and serum-free DMEM/F12 was added to the cell control. The virus was then removed, the cells were washed three times with DPBS, $100 \mu \mathrm{L} /$ well of dilutions of piperine $(200-1.56 \mu \mathrm{g} / \mathrm{mL})$ were added to the wells, serum-free DMEM/F12 medium was added to the control wells, and the plates were incubated for $24 \mathrm{~h}$ at $37^{\circ} \mathrm{C}$ in a $5 \% \mathrm{CO}_{2}$ atmosphere. After $24 \mathrm{~h}$, supernatants from the experimental and control wells with the virus were collected and titrated by TCID 50 assay in Vero cells after incubation for $72 \mathrm{~h}$. The visual assessment of the cytopathogenic effect (CPE) of the virus was performed using an Olympus CKX41 light inverted microscope (Olympus, Tokyo, Japan).

\subsection{Statistical Analysis}

The control $R F_{\mathrm{Ca2}+^{-}}, R F_{F P-M E R S-\mathrm{COV}^{-}}, R F_{F P-S A R S-C O V-2^{-},} t_{1^{-}}$, and $t_{2}$-values, characterizing the vesicle fusion induced by $\mathrm{CaCl}_{2}$, FP-SARS-CoV-2 or FP-MERS-CoV in the absence of alkaloids, were averaged from 5 to 9 independent experiments. The experimental $R F_{S^{-}}, t_{1^{-}}$, and $t_{2}$-values, characterizing the $\mathrm{CaCl}_{2^{-}}$, FP-SARS-CoV-2- and FP-MERS-CoVmediated fusion of liposomes pretreated with different alkaloids, were averaged from 2 to 4 independent experiments. All $R F-, t_{1-}$, and $t_{2}$-values were presented as mean \pm standard error of the mean $(p \leq 0.05)$. The magnitudes of $d, \zeta, T_{m}, T_{1 / 2}$, and $\Delta \varphi_{b}$ were averaged from 3 to 5 independent experiments and presented as mean \pm standard deviation $(p \leq 0.05)$.

To prove the statistical significance of difference between $R F-, t_{1^{-}}, t_{2^{-}}, d-, \zeta_{-}, T_{m^{-}}$, and $T_{1 / 2}$-values at the addition of alkaloids and the control values of related parameters (in the absence of alkaloids) the nonparametric signed-rank U-test (Mann-Whitney-Wilcoxon's U-test) was employed $\left({ }^{*}-p \leq 0.01,{ }^{* *}-p \leq 0.05\right)$.

Pearson's correlation coefficient was applied to estimate the potent relationship between the inhibitory action of alkaloids on the vesicle fusion and the alkaloid-induced alterations in physical properties of lipid bilayers $\left(\Delta T_{m}, \Delta T_{1 / 2}, \Delta \varphi_{b}\right)$. The coefficients were calculated using Microsoft Excel (Microsoft Corp., Redmond, WA, USA).

\section{Results and Discussion}

\subsection{Effect of Alkaloids on $\mathrm{CaCl}_{2}$-Mediated Fusion of Negatively Charged Liposomes}

Figure S4a-c (Supplementary Materials) shows the calcein leakage resulted from $20 \mathrm{mM} \mathrm{CaCl}_{2}$-mediated fusion of DOPG/CHOL-liposomes in the absence and presence of different alkaloids at $400 \mu \mathrm{M}$ concentration ( $40 \mu \mathrm{M}$ of tabersonine). Some alkaloids were able to inhibit calcium-mediated fusion, and this ability strictly depended on the alkaloid type (Figure S4b,c). Table 1 summarizes the mean values of maximum marker leakage caused by calcium-induced fusion of DOPG/CHOL vesicles pretreated by different alkaloids $\left(R F_{S}\right)$. The mean maximum leakage at the addition of fusion inducer alone is about $90 \%$. A significant and reliable decrease in $R F_{S}$ (indicating the inhibition of calcium-mediated fusion) is caused by pretreatment of DOPG/CHOL vesicles with dihydrocapsaicin $\left(R F_{S}\right.$ is about $\left.70 \%\right)$, capsaicin, synephrine $\left(R F_{S}\right.$ is about $\left.50 \%\right)$, 3-isobutyl1-methylxanthine, quinine, piperine $\left(R F_{S}\right.$ is about $\left.30 \%\right)$, tabersonine, hordenine $\left(R F_{S}\right.$ is about $20 \%)$, and lupinine $\left(R F_{S}\right.$ is about $\left.10 \%\right)$. 
Table 1. The parameters characterized the effects of alkaloids on the calcein release caused by the calcium-mediated fusion of liposomes composed of DOPG/CHOL (80/20 mol\%) and DOPC/DOPG/CHOL (40/40/20 mol\%).

\begin{tabular}{|c|c|c|c|c|c|c|}
\hline \multirow[b]{2}{*}{ Alkaloid } & \multicolumn{3}{|c|}{ DOPG/CHOL } & \multicolumn{3}{|c|}{ DOPC/DOPG/CHOL } \\
\hline & $R F_{S}, \%$ & $t_{1}, \min$ & $t_{2}, \min$ & $R F_{S}, \%$ & $t_{1}, \min$ & $t_{2}, \min$ \\
\hline $\mathrm{CaCl}_{2}$ & $92 \pm 7$ & $9 \pm 2$ & $68 \pm 6$ & $82 \pm 1$ & $5 \pm 3$ & $51 \pm 12$ \\
\hline 3,9-dimethylxanthine & $96 \pm 2$ & $2 \pm 1 *$ & $20 \pm 1 *$ & $69 \pm 7$ & $2 \pm 1$ & $82 \pm 21$ \\
\hline caffeine & $94 \pm 5$ & $3 \pm 2$ & $38 \pm 20$ & $65 \pm 8^{*}$ & $1 \pm 1$ & $94 \pm 22$ \\
\hline 7-( $\beta$-hydroxyethyl)theophylline & $94 \pm 6$ & $3 \pm 1$ & $36 \pm 1 *$ & $75 \pm 1$ & $1 \pm 1$ & $75 \pm 31$ \\
\hline colchicine & $94 \pm 4$ & $1 \pm 1^{*}$ & $7 \pm 1 *$ & $87 \pm 3$ & $2 \pm 1$ & $14 \pm 1$ * \\
\hline pentoxifylline & $92 \pm 6$ & $2 \pm 1 *$ & $36 \pm 13$ & $64 \pm 8^{*}$ & $1 \pm 1$ & $60 \pm 14$ \\
\hline cotinine & $87 \pm 12$ & $7 \pm 2$ & $46 \pm 6^{* *}$ & $68 \pm 2 *$ & $3 \pm 1$ & $20 \pm 9 *$ \\
\hline 1,7-dimethylxanthine & $85 \pm 3$ & $8 \pm 4$ & $33 \pm 5 *$ & $60 \pm 15$ & $1 \pm 1$ & $64 \pm 30$ \\
\hline atropine & $81 \pm 6$ & $7 \pm 1$ & $50 \pm 9^{* *}$ & $52 \pm 6^{*}$ & $8 \pm 1$ & $119 \pm 9$ * \\
\hline theophylline & $79 \pm 8$ & $7 \pm 3$ & $61 \pm 19$ & $83 \pm 2$ & $11 \pm 1$ & $97 \pm 7 *$ \\
\hline melatonin & $76 \pm 9$ & $10 \pm 1$ & $119 \pm 24^{*}$ & $84 \pm 8$ & $5 \pm 3$ & $51 \pm 28$ \\
\hline berberine & $74 \pm 11$ & $2 \pm 1 *$ & $27 \pm 6^{*}$ & $92 \pm 6$ & $5 \pm 2$ & $33 \pm 13$ \\
\hline dihydrocapsaicin & $67 \pm 2 *$ & $7 \pm 1$ & $48 \pm 21$ & $56 \pm 4^{*}$ & $2 \pm 1$ & $24 \pm 11$ \\
\hline capsaicin & $53 \pm 9 *$ & $2 \pm 1 *$ & $14 \pm 2 *$ & $56 \pm 2 *$ & $3 \pm 1$ & $14 \pm 5 *$ \\
\hline synephrine & $46 \pm 20 *$ & $5 \pm 1$ & $85 \pm 12$ & $77 \pm 5$ & $12 \pm 4$ & $64 \pm 30$ \\
\hline 3-isobutyl-1-methylxanthine & $32 \pm 12 *$ & $3 \pm 1 *$ & $68 \pm 12$ & $84 \pm 4$ & $9 \pm 1$ & $80 \pm 24$ \\
\hline quinine & $27 \pm 4^{*}$ & $3 \pm 1 * *$ & $118 \pm 23^{* *}$ & $66 \pm 3 *$ & $3 \pm 1$ & $27 \pm 10$ \\
\hline piperine & $27 \pm 10 *$ & $2 \pm 1^{*}$ & $27 \pm 11^{* *}$ & $24 \pm 1 *$ & $2 \pm 1$ & $8 \pm 2 *$ \\
\hline tabersonine & $21 \pm 7^{*}$ & $2 \pm 1 *$ & $11 \pm 2 *$ & $1 \pm 1 *$ & $-\&$ & $-\&$ \\
\hline hordenine & $20 \pm 16^{*}$ & $1 \pm 1 *$ & $17 \pm 6^{*}$ & $82 \pm 4$ & $4 \pm 3$ & $50 \pm 17$ \\
\hline lupinine & $13 \pm 10 *$ & $1 \pm 1^{*}$ & $90 \pm 12$ & $38 \pm 4^{*}$ & $6 \pm 3$ & $42 \pm 3$ \\
\hline
\end{tabular}

$R F_{S}$ - the maximum leakage of fluorescent marker caused by the fusion of liposomes composed of DOPG/CHOL (80/20 mol\%) and DOPC/DOPG/CHOL (40/40/20 mol\%) mediated by 20 and $40 \mathrm{mM} \mathrm{CaCl}_{2}$ respectively. Liposomes have been incubated with $400 \mu \mathrm{M}$ of alkaloids (except for $40 \mu \mathrm{M}$ of tabersonine) for $30 \mathrm{~min}$ before the addition of $\mathrm{CaCl}_{2} \cdot t_{1}$ and $t_{2}$ - the time constants characterizing the fast (1) and slow (2) components of marker release kinetics (the time dependences of marker leakage were fitted by two-exponential functions). ${ }^{*} \_p \leq 0.01,{ }^{* *}-p \leq 0.05$ (Mann-Whitney-Wilcoxon's test, $\mathrm{CaCl}_{2}$ alone vs. $\mathrm{CaCl}_{2}+$ alkaloid). \& — cannot be determined.

Table 1 also demonstrates the kinetic parameters of liposome fusion in the presence of alkaloids. It should be noted that the time dependences of the marker release due to vesicle fusion are well-described by two-exponential dependences with characteristic times related to fast and slow components ( $t_{1}$ and $t_{2}$, respectively). Analysis of Table 1 indicates that $t_{1}$ and $t_{2}$ values vary in the ranges of about 1-10 and 10-120 min, respectively. The fast component might characterize the calcium sorption on the negatively charged DOPGenriched membranes and the subsequent aggregation of the lipid vesicles, while the slow one might be related to the topological rearrangements of membrane lipids and further dye leakage at the liposome fusion. Colchicine, capsaicin, and tabersonine significantly accelerated the marker release kinetics at calcium-mediated fusion of DOPG/CHOL vesicles (about 5-10-fold decrease in both characteristic times is observed) (Table 1). Melatonin and quinine drastically slowed down the fusion process increasing $t_{2}$ from about 70 to more than 100 min (Table 1).

To characterize the relative efficiency of different alkaloids to inhibit calcium-mediated DOPG/CHOL liposome fusion the inhibition index (II) was calculated using Formula (2) for single preparation of liposome suspension, and then was averaged between the various preparations (Figure 1a). Taking into account the II value, the tested alkaloids were divided into three groups: ineffective (II does not exceed 15\%); of low and medium efficiency 
(II is in the range of $16-50 \%$ ), and of high efficiency (II is more than $50 \%$ ). The first group includes 3,9-dimethylxanthine, caffeine, 7-( $\beta$-hydroxyethyl)theophylline, colchicine, pentoxifylline, cotinine, 1,7-dimethylxanthine, atropine, theophylline, melatonin, and berberine. The efficiency in the second group increases in the series: dihydrocapsaicin (II is about $25 \%$ ) $\leq$ capsaicin $\approx$ synephrine (II is about $45 \%$ ). The latter (the most effective) group includes 3-isobutyl-1-methylxanthine (II is about $65 \%$ ), piperine $\approx$ quinine (II is about $70 \%$ ), tabersonine (II is about $75 \%$ ), hordenine (II is about $80 \%$ ), and lupinine (II is about $85 \%$ ).
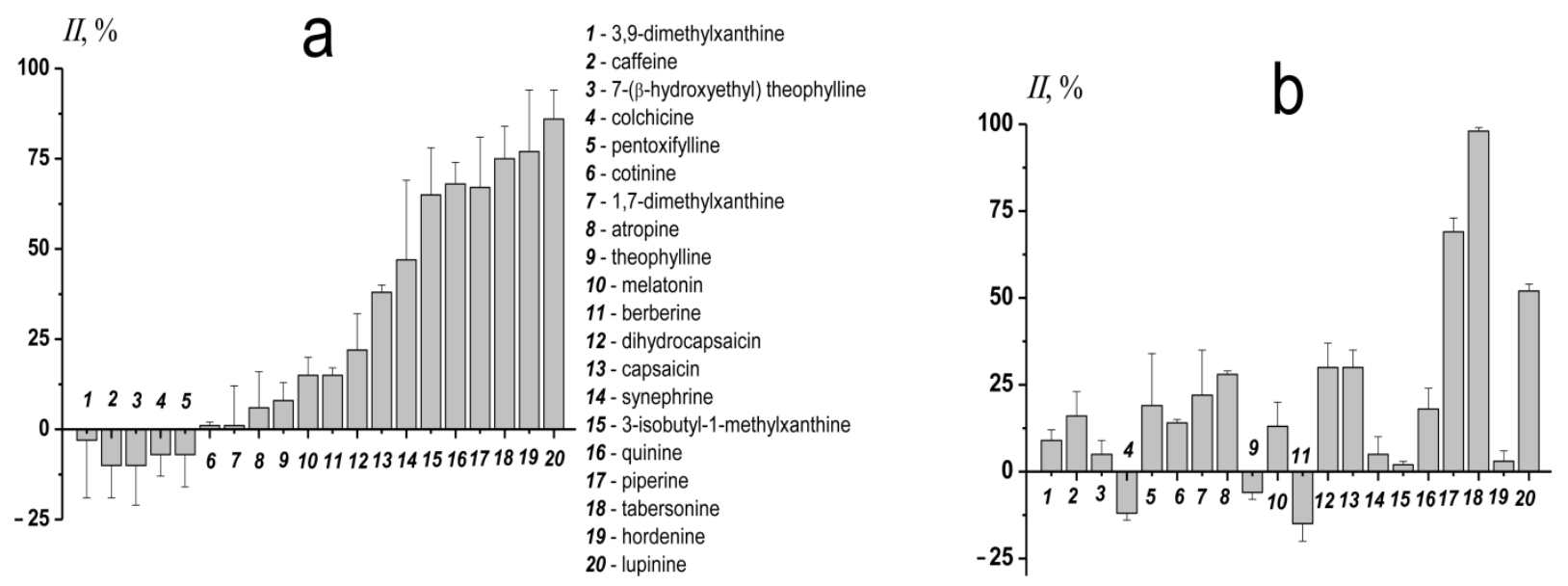

Figure 1. The inhibition index (II) characterizing the ability of tested alkaloids to suppress the fusion of vesicles made from DOPG/CHOL (80/20 mol\%) (a) and DOPC/DOPG/CHOL (40/40/20 mol\%) (b). Liposomes were incubated with $400 \mu \mathrm{M}$ of alkaloids (except for $40 \mu \mathrm{M}$ of tabersonine) for $30 \mathrm{~min}$ before the addition of $\mathrm{CaCl}_{2}$.

Figure 2a shows the results of size measurements after calcium addition to unmodified DOPG/CHOL liposomes and vesicles pretreated by alkaloids of various anti-fusogenic activity, cotinine, melatonin, 3-isobutyl-1-methylxanthine, lupinine, piperine, tabersonine, and hordenine. The diameter of DOPG/CHOL liposomes in the absence of any modifiers is equal to $80 \pm 20 \mathrm{~nm}$. $\mathrm{CaCl}_{2}$ induces liposome fusion, and the vesicle size increased up to $145 \pm 40 \mathrm{~nm}$ (Figure 2a). Cotinine and melatonin practically did not affect the sizeincreasing effect of calcium, as the liposome diameter was about $140 \mathrm{~nm}$. The other tested compounds (lupinine, 3-isobutyl-1-methylxanthine, tabersonine, piperine, and hordenine) significantly inhibited calcium-mediated liposome fusion: the diameter of the vesicles was equal to $77 \pm 13 \mathrm{~nm}$ (Figure $2 \mathrm{a}$ ). The data obtained are in good agreement with the II values assessed by the calcein release assay (Figure 1a).

Figure $2 b$ presents the results of estimation of the $\zeta$-potential of DOPG/CHOL liposomes in the presence of $20 \mathrm{mM} \mathrm{CaCl}_{2}$ without and with different alkaloids. The $\zeta$-potential of unmodified DOPG/CHOL liposomes was equal to about $-70 \mathrm{mV}$. The addition of calcium led to an increase in $\zeta$-potential up to about $-50 \mathrm{mV}$. The $\zeta$-potential value of DOPG/CHOL vesicles pretreated with alkaloids was $10-20 \mathrm{mV}$ less than that of untreated ones (Figure $2 \mathrm{~b}$ ). The observed incomplete compensation of negative surface charge of DOPG-enriched liposomes was expected at the introduction of positively charged calcium ions and alkaloid molecules (lupinine, tabersonine, and hordenine). The disagreement of alkaloid abilities to inhibit calcium-mediated vesicle fusion and to increase $\zeta$-potential (Figure 2a,b) clearly demonstrates that the anti-fusogenic activity of alkaloids is not due to partial compensation of the negative membrane surface charge by alkaloids or a competition between alkaloids and calcium ions for the interaction with negatively charged lipid groups. 

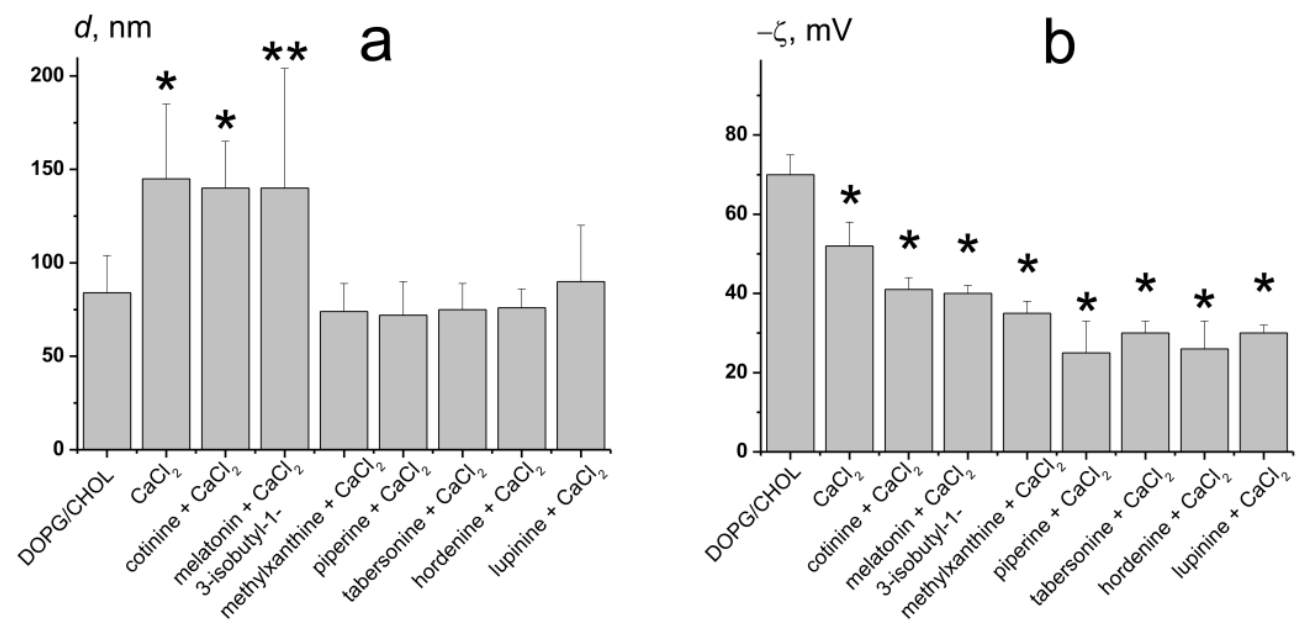

Figure 2. The diameter $(d, \mathrm{~nm})(\mathbf{a})$ and the $\zeta$-potential $(\mathbf{b})$ of the DOPG/CHOL $(80 / 20 \mathrm{~mol} \%)$ liposomes before and after addition of $20 \mathrm{mM} \mathrm{CaCl}_{2}$ to unmodified vesicles and liposomes pretreated by $400 \mu \mathrm{M}$ of cotinine, melatonin, 3-isobutyl-1-methylxanthine, lupinine, piperine, hordenine, or $40 \mu \mathrm{M}$ of tabersonine. ${ }^{*}-p \leq 0.01,{ }^{* *}-p \leq 0.05$ (Mann-Whitney-Wilcoxon's test, untreated liposomes vs. vesicles in the presence of $\mathrm{CaCl}_{2}$ or/and alkaloids).

To study the dependence of the inhibition effect of alkaloids on the lipid composition of fusing vesicles, DOPC was introduced into membrane composition. It should be noted that the cell membranes are enriched of phosphatidylcholine species compared to virions $[47,55,56]$. The decrease in the proportion of negatively charged DOPG in membrane composition from 80 to $40 \mathrm{~mol} \%$ was accompanied by an increase in $\mathrm{CaCl}_{2}$ concentration from 20 to $40 \mathrm{mM}$ to reach the $R F_{S}$ value of about $80 \%$. Figure S4d-f (Supplementary Materials) demonstrates the calcein leakage caused by the calcium-mediated fusion of DOPC/DOPG/CHOL liposomes. $R F_{S}$ resulted from calcium-mediated fusion of DOPC/DOPG/CHOL vesicles pretreated by different alkaloids reliably decreases in the series: caffeine $\approx$ pentoxifylline $\approx$ cotinine $\approx$ quinine $\left(R F_{S}\right.$ is about $\left.65 \%\right) \geq$ atropine $\approx$ dihydrocapsaicin $\approx$ capsaicin $\left(R F_{S}\right.$ is about $\left.55 \%\right)>$ lupinine $\left(R F_{S}\right.$ is about $\left.40 \%\right)>$ piperine $\left(R F_{S}\right.$ is about $\left.25 \%\right)>$ tabersonine $\left(R F_{S}\right.$ is equal to $1 \%$ ) (Table 1$)$.

The kinetic parameters of the time dependence of the calcein leakage caused by calciummediated fusion of DOPC/DOPG/CHOL liposomes are shown in Table 1. Colchicine and capsaicin accelerate the release kinetics due to calcium-mediated fusion of DOPC/DOPG/CHOL vesicles as well as of DOPG/CHOL liposomes. The huge inhibition of calcium-mediated fusion of DOPC/DOPG/CHOL liposomes in the presence of tabersonine did not allow for determining the characteristic times of dye release kinetics. Similar to DOPG/Chol vesicles, the pretreatment of DOPC/DOPG/CHOL liposomes with colchicine and capsaicin led to about five-fold decrease in $t_{2}$-value. Unlike the case of DOPG/CHOL vesicles, the kinetics of calcein leakage due to fusion of DOPC/DOPG/CHOL liposomes was also accelerated by piperine (by six times), while theophylline and atropine slightly slowed down the fusion process, increasing $t_{2}$ from 50 to about 100 and $120 \mathrm{~min}$, respectively (Table 1).

Figure $1 \mathrm{~b}$ shows the $I I$ values, characterizing the relative ability of different alkaloids to suppress the fusion of DOPC/DOPG/CHOL vesicles. Moreover, 3,9-dimethylxanthine, 7-( $\beta$-hydroxyethyl)theophylline, colchicine, 1,7-dimethylxanthine, theophylline, melatonin, berberine, synephrine, 3-isobutyl-1-methylxanthine, and hordenine did not demonstrate a significant ability to inhibit the fusion of DOPC/DOPG/CHOL liposomes. Caffeine, pentoxifylline, cotinine, atropine, dihydrocapsaicin, capsaicin, and quinine were characterized by low or medium efficiency to suppress the fusion of vesicles made of ternary lipid mixture, while the II values in the presence of lupinine, piperine, and tabersonine were about 50,70 , and $100 \%$ (Figure $1 \mathrm{~b}$ ). Comparison of Figure 1a,b clearly demonstrates that the anti-fusogenic activity of alkaloids strictly depends on the lipid composition of the vesicles. 


\subsection{The Influence of Alkaloids on the Physical Properties of the Model Lipid Membrane}

It has been repeatedly shown that the elastic characteristics of the lipid bilayer play a huge role in the membrane fusion. The ordering of the lipid head groups and acyl chains, transbilayer lateral pressure profile, phase state of lipids, spontaneous curvature of the membrane, area per lipid molecule, and other characteristics can influence fusion [57]. Many of these parameters influence each other, but all of them are directly dependent on the lipid composition of the membrane. The key role of lipids is also supported by the fact that viral infections can alter cell lipid synthesis, regulating it according to their needs [58]. The ability of alkaloids and their derivatives to change the physical properties of a bilayer upon intercalation was demonstrated in a number of studies [59-62]. In particular, alkaloids affect the lipid packing $[63,64]$, change lipid phase transition temperatures $[65,66]$, etc. Recently, we performed a detailed study of alkaloid effects on the physical properties of the POPC membrane [67]. To understand the relationship between the alkaloid effects on the fusion and modulation of lipid matrix under their action, the influence of tested alkaloids on the properties of PG and CHOL-enriched bilayers were performed.

Figure 3 presents the typical heating thermograms of DPPG/CHOL-liposomes in the absence (control) and in the presence of tested alkaloids. The value of the phase transition temperature $\left(T_{m}\right)$ of DPPG/CHOL mixture, and the half-width of the main peak $\left(T_{1 / 2}\right)$ are summarized in Table 2. $T_{m}$ is the point at which thermally induced lipid melting occurs [68], while $T_{1 / 2}$ describes the sharpness of the phase transition or the inverse cooperativity of this process [69]. The temperature of the main transition $\left(T_{m}\right)$ of untreated DPPG/CHOL vesicles is equal to $40.4{ }^{\circ} \mathrm{C}$, with a half-width of the peak $\left(T_{1 / 2}\right)$ of about $0.8^{\circ} \mathrm{C}$ (Figure 3 , control).

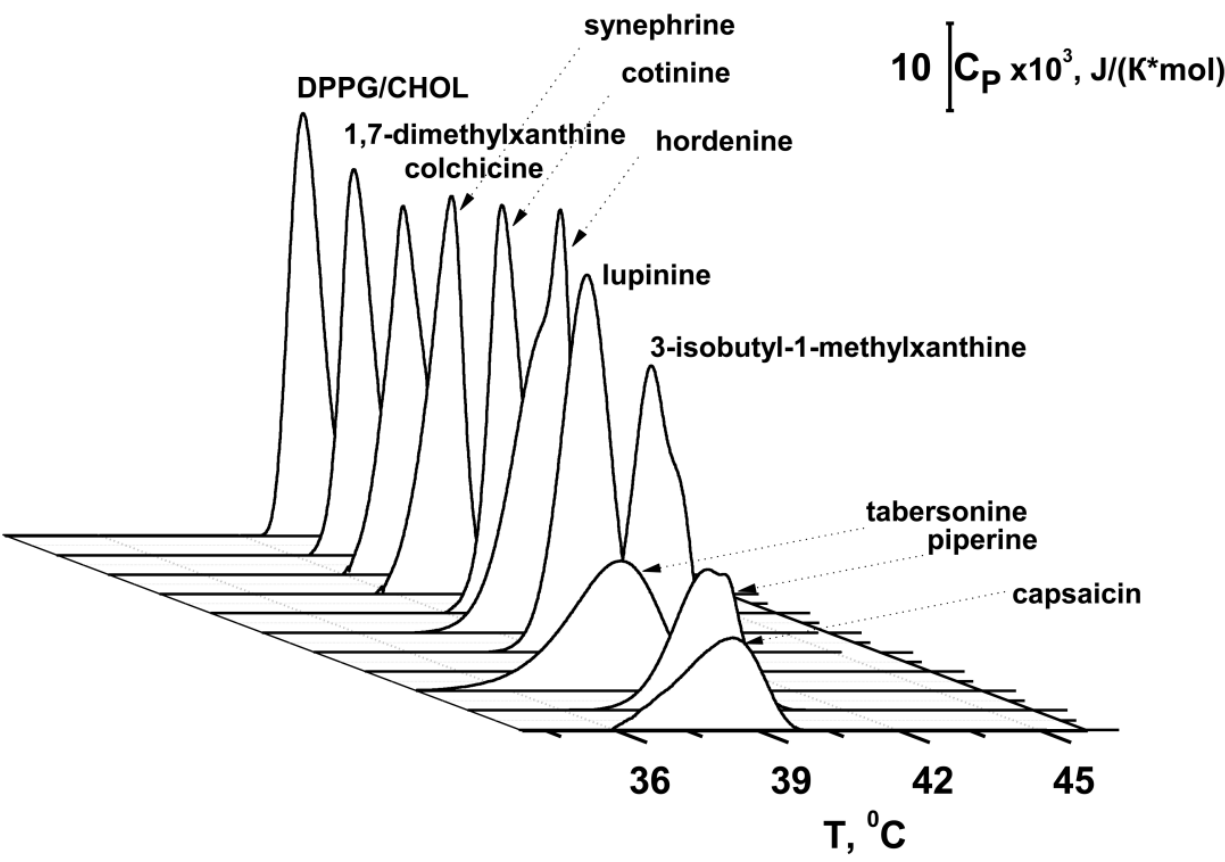

Figure 3. Heating thermograms of DPPG/CHOL (90/10 mol\%) liposomes in the absence and presence of $400 \mu \mathrm{M}$ of 1,7-dimethylxanthine, piperine, hordenine, cotinine, 3-isobutyl-1-methylxanthine, lupinine, synephrine, capsaicin, colchicine, and $40 \mu \mathrm{M}$ of tabersonine. 
Table 2. The parameters characterized the effects of alkaloids on the physical properties of lipid bilayers: $T_{m}$-the main transition temperature of DPPG/CHOL $(90 / 10 \mathrm{~mol} \%) ; T_{1 / 2}$-the half-width of the main peak in the presence of $400 \mu \mathrm{M}$ of alkaloids ( $40 \mu \mathrm{M}$ of tabersonine); $\Delta \varphi_{b}(\max )$-the maximum changes in the boundary potential of DOPG/CHOL $(80 / 20 \mathrm{~mol} \%)$ membranes.

\begin{tabular}{|c|c|c|c|}
\hline Alkaloid & $\mathrm{T}_{m},{ }^{\circ} \mathrm{C}$ & $T_{1 / 2},{ }^{\circ} \mathrm{C}$ & $\Delta \varphi_{b}(\max ), \mathrm{mV}$ \\
\hline control & $40.4 \pm 0.0$ & $0.8 \pm 0.0$ & - \\
\hline colchicine & $40.4 \pm 0.0$ & $0.8 \pm 0.0$ & $-24 \pm 6$ \\
\hline cotinine & $40.4 \pm 0.0$ & $0.8 \pm 0.0$ & $-7 \pm 3$ \\
\hline 1,7-dimethylxanthine & $40.4 \pm 0.0$ & $0.8 \pm 0.0$ & $-5 \pm 2$ \\
\hline capsaicin & $38.3 \pm 0.2 *$ & $2.0 \pm 0.1 *$ & $-70 \pm 7$ \\
\hline synephrine & $40.1 \pm 0.1$ * & $1.2 \pm 0.1$ * & $-25 \pm 3$ \\
\hline 3-isobutyl-1-methylxanthine & $39.9 \pm 0.2 *$ & $1.2 \pm 0.1 *$ & $-18 \pm 4$ \\
\hline piperine & $39.5 \pm 0.3^{*}$ & $1.5 \pm 0.2 *$ & $-39 \pm 8$ \\
\hline tabersonine & $38.5 \pm 0.2 *$ & $1.9 \pm 0.2$ * & $58 \pm 9$ \\
\hline hordenine & $39.7 \pm 0.2$ * & $1.2 \pm 0.1$ * & $8 \pm 3$ \\
\hline lupinine & $39.7 \pm 0.1$ * & $1.5 \pm 0.2 *$ & $-30 \pm 3$ \\
\hline
\end{tabular}

*—p $\leq 0.01$ (Mann-Whitney-Wilcoxon's test, control vs. alkaloid).

Colchicine, cotinine, and 1,7-dimethylxanthine did not affect the thermotropic phase behavior of DPPG/CHOL mixture (Figure 3, Table 2). Synephrine, 3-isobutyl-1-methylxanthine, lupinine, and hordenine decreased the $T_{m}$ by approximately 0.3 to $0.7{ }^{\circ} \mathrm{C}$ and increased the $T_{1 / 2}$ by 0.4 to $0.6{ }^{\circ} \mathrm{C}$ (Figure 3, Table 2). The data are in agreement with the study of hordenine influence on the phase behavior of dimyristoylphosphatidylglycerol [61]. The introduction of capsaicin, piperine, and tabersonine was accompanied by a sharp decrease in $T_{m}\left(0.9-2.1^{\circ} \mathrm{C}\right)$ and increase in $T_{1 / 2}\left(0.7-1.2{ }^{\circ} \mathrm{C}\right)$ (Figure 3, Table 2). The correlation coefficients between $\log D_{o / w}$ (Table S1 Supplementary Materials) and $-\Delta T_{m^{-}}$ and $\Delta T_{1 / 2}$-values (Table 2 ) are in the range of $0.74-0.77$, demonstrating a good correlation between the lipophilicity of the alkaloid molecules and their ability to alter lipid packing.

The correlation coefficient between the alkaloid-induced changes in $T_{m}$ of DPPG/CHOL (Table 2) and their II values in DOPG/CHOL vesicles (Figure 1a) was equal to 0.52, the corresponding coefficient characterizing the interdependence of alkaloid-induced changes in $T_{1 / 2}$ (Table 2) and the II values (Table 1) was equal to 0.63 . The correlation coefficient between the alkaloid-induced changes in $T_{m}$ (Table 2) and their II values in DOPC/DOPG/CHOL vesicles (Table 1) was equal to 0.64 , while the interdependence of compound-induced changes in $T_{1 / 2}$ (Table 2) and alkaloid II values of DOPC/DOPG/CHOL liposomes (Figure 1b) was characterized by a coefficient of 0.68 . The observed correlation between the parameters characterizing the lipid melting, especially the cooperativity of lipid phase transition, and the fusion inhibition index indicates a relationship between the ability of alkaloids to disorder membrane lipids and to inhibit the liposome fusion. The incorporation of alkaloids into the polar region of the membrane, leading to an increase in lateral pressure, positive curvature stress, and an area per lipid molecule in this region, contributes to both a reduction in the temperature/cooperativity of the phase transition and an increase in the energy of fusion intermediates characterized by lipid surfaces of a negative curvature. Moreover, a comparison of the data obtained (Figure 3, Table 2) and our recently published results [65] demonstrate that the tested alkaloids have different effects on the phase behavior of DPPG/CHOL and DPPC. This fact might be related to the observed difference in their ability to inhibit the fusion of DOPG/CHOL and DOPC/DOPG/CHOL vesicles (Figure 1, Table 1). Alkaloid-induced curvature stress should depend on the depth of molecule insertion into lipid bilayer and its orientation in the membrane. The significant inhibitory action of 3-isobutyl-1-methylxanthine on the fusion of DOPG/CHOL liposomes might be related to the induction of the high posi- 
tive curvature stress due to both the electrostatic interaction between xanthine residue and DOPG on the membrane surface and the tendency of the isobutyl side chain to be embedded into the membrane hydrocarbon core. Xanthine derivatives with lower hydrophobicity, i.e., caffeine, pentoxifylline, 1,7-dimethylxanthine, 3,9-dimethylxanthine, and 7-( $\beta$-hydroxyethyl)theophylline (Table S1, Supplementary Materials) did not inhibit calcium-mediated fusion of DOPG/CHOL liposomes. Introduction of DOPC into the membrane lipid composition was accompanied by a two-fold decrease in the DOPG content, which led to significant changes in the membrane orientation and embedment of xanthines. Thus, caffeine and pentoxifylline demonstrated a weak inhibitory effect on a fusion of DOPC/DOPG/CHOL vesicles, while 3-isobutyl-1-methylxanthine did not affect this process. The complete loss of the inhibiting ability of $\beta$-phenylethylamine derivatives, synephrine and hordenine, in membranes with lower content of DOPG compared to DOPGenriched bilayers, could be explained in a similar way. An increase in the inhibitory effect of tabersonine on the fusion of DOPC/DOPG/CHOL vesicles compared to DOPG/CHOL liposomes might indicate its deeper immersion into the DOPC/DOPG/CHOL membranes than into DOPG/CHOL bilayers due to a decrease in the electrostatic interactions between positively charged tabersonine and negatively charged DOPG molecules.

Considering that liposome fusion is triggered by calcium ions, we also considered the possibility of alkaloids influencing fusion by changing the boundary potential of the membranes. Table 2 shows the maximum changes in $\varphi_{b}$ at the adsorption of different alkaloids $\left(-\Delta \varphi_{b}(\max )\right)$. The dependences of $\Delta \varphi_{b}$ on the concentrations of tested alkaloids are presented in Figure S5 (Supplementary Materials). Tabersonine significantly increased the $\varphi_{b}$ of DOPG/CHOL membranes (by about $60 \mathrm{mV}$ ), while capsaicin dramatically decreased this value (by about $-70 \mathrm{mV}$ ) (Figure S5 in the Supplementary Materials, Table 2). Colchicine, synephrine, 3-isobutyl-1-methylxanthine, lupinine, and piperine led to reduction in $\varphi_{b}$ by about 20-40 mV (Figure S5 in the Supplementary Materials, Table 2). Cotinine, 1,7-dimethylxanthine, and hordenine practically did not alter the $\varphi_{b}$-value (Figure S5 Supplementary Materials, Table 2). There was no correlation between $\Delta \varphi_{b}$ of DOPG/CHOL membranes after the addition of alkaloids and their II values. This fact demonstrates the minor role of changes in the bilayer electrical properties by alkaloids in their ability to inhibit the calcium-mediated membrane fusion.

\subsection{Liposome Fusion Mediated by Fragments of Coronavirus Fusion Peptides}

The COVID-19 pandemic has caused major challenges to healthcare systems across the globe. The lack of specific treatment, virus mutations, the emergence of new strains that have become resistant to vaccines, and many other factors, have led to the search for new drugs to treat COVID-19. To demonstrate the pharmacological applications of alkaloids as coronavirus fusion inhibitors - the abilities of the most effective compounds to suppress the membrane fusion induced by FP-MERS-CoV and FP-SARS-CoV-2 were studied. These peptides are able to induce calcein release due to fusion of POPC/SM/CHOL liposomes (Figure S2c,d Supplementary Materials), and are not effective to produce the fusion of DOPG/CHOL vesicles (data not shown).

To further validate the fusogenic properties of FP-MERS-CoV and FP-SARS-CoV-2, the confocal fluorescence microscopy of giant unilamellar vesicles composed of POPC/SM/CHOL was performed. Figure 4 presents the fluorescence micrographs of POPC/SM/CHOL liposomes in the absence (Figure $4 \mathrm{a}$ ) and presence of $10 \%$ of the well-established fusion inducer PEG-8000 (Figure 4b), 50 M FP-SARS-CoV-2 (Figure 4c), and $200 \mu \mathrm{M}$ FP-MERS$\mathrm{CoV}$ (Figure $4 \mathrm{~d}$ ). Both peptides at the indicated concentrations caused deformation and aggregation of lipid vesicles, and increased in size. FP-SARS-CoV-2, unlike FP-MERS-CoV, also induced the formation of multilamellar and multivesicular liposomes (Figure 4c). In general, the morphological picture under the action of both peptides is similar to that which occurred when PEG-8000 was added (Figure 4b). Thus, the results obtained confirm the fusogenic activity of FP-SARS-CoV-2 and FP-MERS-CoV. 
a

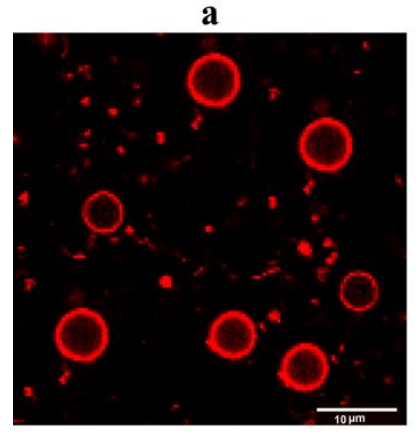

b

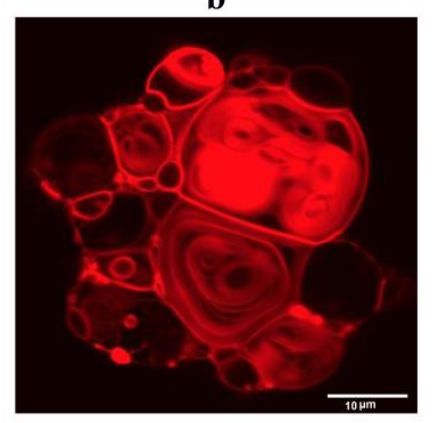

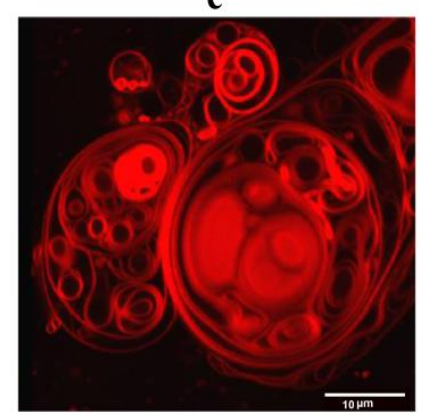

d

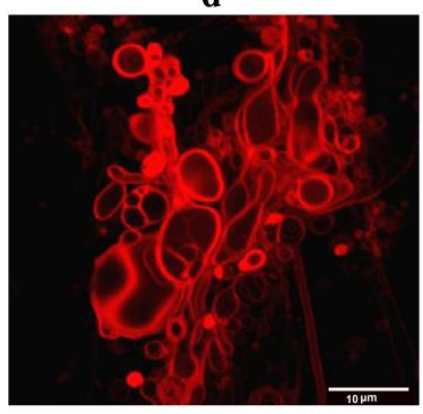

Figure 4. Fluorescence micrographs of giant unilamellar vesicles made from POPC/SM/CHOL (60/20/20 mol\%) and $1 \mathrm{~mol} \%$ of fluorescent lipid probe Rh-DPPE in the absence of any modifiers (a), and in the presence of $10 \%$ of PEG-8000 (b), $50 \mu \mathrm{M}$ of FP-SARS-CoV-2 (c), and $200 \mu \mathrm{M}$ of FP-MERS-CoV (d).

Figure $5 \mathrm{a}$,d present the effects of alkaloids that effectively inhibit calcium-mediated fusion of DOPG/CHOL vesicles, 3-isobutyl-1-methylxanthine, piperine, tabersonine, hordenine, and lupinine, on the calcein leakage caused by FP-SARS-CoV-2- and FP-MERS-CoVmediated fusion of POPC/SM/CHOL liposomes, respectively. In the absence of alkaloids $R F_{s}$-value produced by $50 \mu \mathrm{M}$ of FP-SARS-CoV-2 and $200 \mu \mathrm{M}$ of FP-MERS-CoV was about 70 (Figure $5 \mathrm{a}$ ) and $80 \%$ (Figure $5 \mathrm{~d}$ ), respectively. Table 3 summarizes the mean values of maximum marker leakage caused by peptide-induced fusion of POPC/SM/CHOL vesicles pretreated by different alkaloids and the kinetic parameters of liposome fusion in the presence of alkaloids. $R F_{S}$ caused by FP-SARS-CoV-2-mediated fusion of POPC/SM/CHOL vesicles significantly decreased in the presence of piperine $\left(R F_{S}\right.$ is about $\left.30 \%\right)$ and tabersonine $\left(R F_{S}\right.$ is about $\left.50 \%\right)$. Moreover, piperine was also effective against FP-MERS-CoVmediated fusion $\left(R F_{S}\right.$ is about $30 \%$ ), while tabersonine was not characterized by an ability to inhibit FP-MERS-CoV-mediated fusion of POPC/SM/CHOL liposomes. The fusioninduced leakage in the presence of 3-isobutyl-1-methylxanthine, tabersonine, hordenine, and lupinine was characterized by faster kinetics compared to the absence of alkaloids, while highly active piperine slightly slowed down kinetics of FP-MERS-CoV-induced fusion by increasing $t_{2}$-value.

Figure 5 b,e show the alkaloid $I I$-values clearly demonstrating the ability of piperine to significantly inhibit both FP-SARS-CoV-2- and FP-MERS-CoV-mediated fusion of $\mathrm{POPC} / \mathrm{SM} / \mathrm{CHOL}$ liposomes, and the selectivity of tabersonine anti-fusogenic action. The observed selectivity of tabersonine action against liposome fusion induced by FP-SARSCoV-2 and FP-MERS-CoV should be researched further.

To further demonstrate the anti-fusogenic activity of piperine, the vesicle size before and after the addition of FP-SARS-CoV-2 and FP-MERS-CoV to the unmodified and alkaloid pretreated POPC/SM/CHOL-liposomes was measured by dynamic light scattering (Figure $5 \mathrm{c}, \mathrm{f})$. In the absence of the any modifiers, the diameters of POPC/SM/CHOLvesicles were equal to $110 \pm 15 \mathrm{~nm}$. Addition of the peptide FP-SARS-CoV-2 and FPMERS-CoV led to an increased in size, up to $290 \pm 40 \mathrm{~nm}$ and $190 \pm 15 \mathrm{~nm}$, respectively (Figure $5 \mathrm{c}, \mathrm{f}$ ). In the presence of piperine, the modeling fusion peptides were not able to increase the diameter of POPC/SM/CHOL-liposomes due to strong inhibition of vesicle fusion by the alkaloid. Figure $5 \mathrm{c}$ also demonstrates the ability of tabersonine to prevent the increase of liposome size under FP-SARS-CoV-2 action. The invariability of the liposome $\zeta$ potential upon the addition of FP-SARS-CoV-2- and FP-MERS-CoV to both unmodified and alkaloid pretreated POPC/SM/CHOL liposomes is shown in Figure S6 (Supplementary Materials). 


\section{FP-SARS-CoV-2}
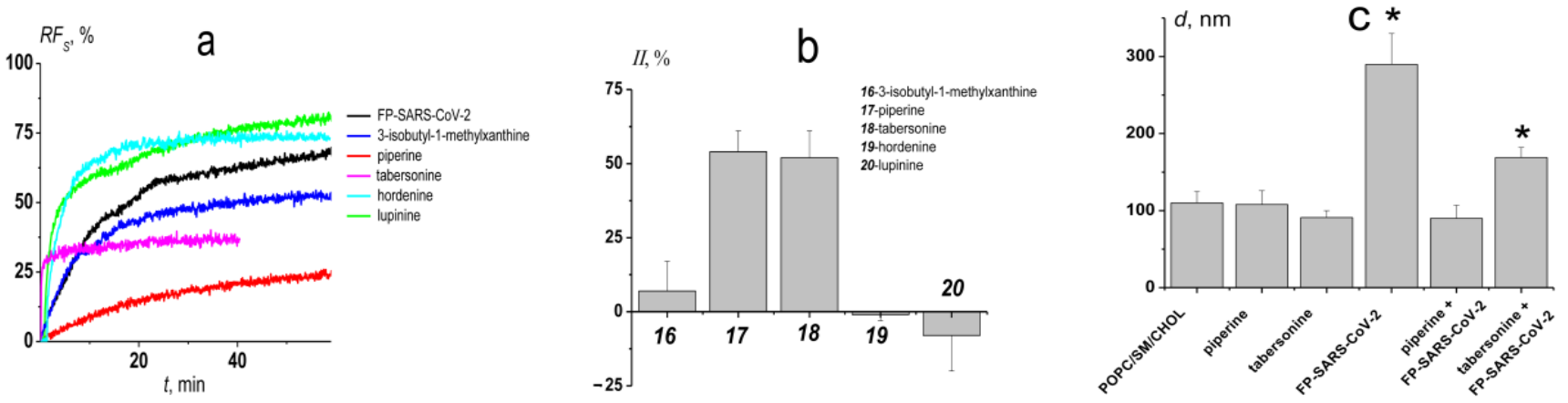

\section{FP-MERS-CoV}
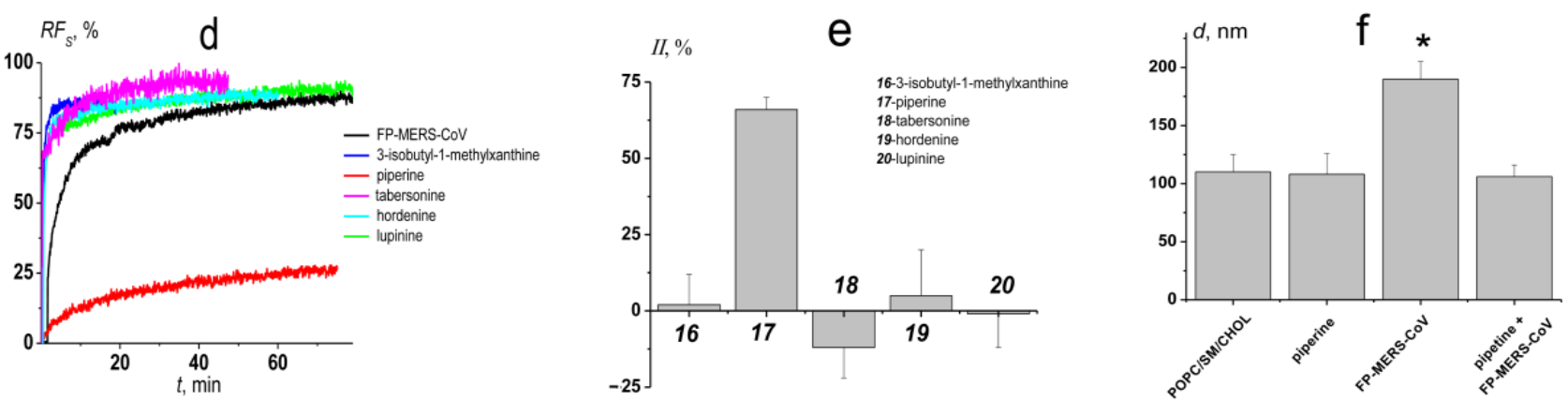

Figure 5. The effects of the alkaloids on FP-SARS-CoV-2 (upper panel) and FP-MERS-CoV (lower panel) mediated fusion of POPC/SM/CHOL (60/20/20 mol\%) vesicles. (a,d) The time dependence of relative fluorescence of calcein $\left(R F_{S}, \%\right)$ leaked due to the fusion induced by $50 \mu \mathrm{M}$ of FP-SARS-CoV-2; (a) and $200 \mu \mathrm{M}$ of FP-MERS-CoV; (d) in the absence and presence of alkaloids. Liposomes were incubated with $400 \mu \mathrm{M}$ of alkaloids for $30 \mathrm{~min}$ before addition of the peptides. The relationship between the color line and the alkaloid is given in the figure. (b,e) The inhibition index (II) characterizing the ability of tested alkaloids to suppress the fusion induced by $50 \mu \mathrm{M}$ of FP-SARS-CoV-2 (b); and $200 \mu \mathrm{M}$ of FP-MERS-CoV (e). (c,f) The diameter $(d, \mathrm{~nm})$ of the POPC/SM/CHOL liposomes before and after addition of $50 \mu \mathrm{M}$ of FP-SARS-CoV-2 (c) and $200 \mu \mathrm{M}$ of FP-MERS-CoV (f) to vesicles pretreated with $400 \mu \mathrm{M}$ of piperine or tabersonine. ${ }^{*}-p \leq 0.01$ (Mann-Whitney-Wilcoxon's test, untreated liposomes vs. vesicles in the presence of fusion peptides or/and alkaloids).

Table 3. The parameters characterized the effects of alkaloids on the calcein release caused by the FP-SARS-CoV-2 and FP-MERS-CoV-mediated fusion of liposomes composed of POPC/SM/CHOL.

\begin{tabular}{|c|c|c|c|c|c|c|}
\hline \multirow[b]{2}{*}{ Alkaloid } & \multicolumn{3}{|c|}{$50 \mu \mathrm{M}$ FP-SARS-CoV-2 } & \multicolumn{3}{|c|}{$200 \mu \mathrm{M}$ FP-MERS-CoV } \\
\hline & $R F_{S}, \%$ & $t_{1}, \min$ & $t_{2}, \min$ & $R F_{S}, \%$ & $t_{1}, \min$ & $t_{2}, \min$ \\
\hline inducer & $77 \pm 6$ & $11 \pm 1$ & $70 \pm 4$ & $80 \pm 5$ & $3 \pm 2$ & $22 \pm 14$ \\
\hline 3-isobutyl-1-methylxanthine & $66 \pm 5$ & $3 \pm 1 *$ & $15 \pm 2 *$ & $78 \pm 6$ & $2 \pm 1$ & $15 \pm 5$ \\
\hline piperine & $33 \pm 3 *$ & $9 \pm 3$ & $73 \pm 6$ & $29 \pm 2^{*}$ & $4 \pm 1$ & $48 \pm 1$ * \\
\hline tabersonine & $53 \pm 9^{* *}$ & $1 \pm 1^{*}$ & $27 \pm 13 *$ & $79 \pm 7$ & $2 \pm 1$ & $12 \pm 2$ \\
\hline hordenine & $74 \pm 8$ & $3 \pm 1^{*}$ & $18 \pm 4 *$ & $75 \pm 10$ & $2 \pm 1$ & $21 \pm 1$ \\
\hline lupinine & $76 \pm 4$ & $1 \pm 1^{*}$ & $31 \pm 9 *$ & $80 \pm 6$ & $1 \pm 1$ & $26 \pm 1$ \\
\hline
\end{tabular}

$R F_{S}$ - the maximum leakage of fluorescent marker caused by the fusion of liposomes composed of POPC/SM/CHOL (60/20/20 mol\%) mediated by $50 \mu \mathrm{M}$ FP-SARS-CoV-2 or $200 \mu \mathrm{M}$ FP-MERS-CoV. Liposomes have been incubated with $400 \mu \mathrm{M}$ of alkaloids for 30 min before the addition of $\mathrm{CaCl}_{2} . t_{1}$ and $t_{2}$-the time constants characterizing the fast (1) and slow (2) components of marker release kinetics (the time dependences of marker leakage were fitted by two-exponential functions). ${ }^{*}-p \leq 0.01,{ }^{* *}-p \leq 0.05$ (Mann-Whitney-Wilcoxon's test, fusion peptide alone vs. fusion peptide + alkaloid). 


\subsection{Antiviral Evaluation}

Piperine is an alkaloid found in black pepper, one of the most widely used spices. The in vitro and in vivo antiviral activity of the alkaloid against the MERS-CoV in Vero cells, and in a mice model, was already demonstrated [70]. Here, we evaluated in vitro antiviral activity of piperine against the SARS-CoV-2 virus.

According to results of the cytotoxicity analysis performed by Hegeto et al. [71], the value of $I C_{50}$ of piperine against Vero cells was equal to $183.33 \mu \mathrm{g} / \mathrm{mL}$. Based on this finding, the maximum piperine concentration of $200 \mu \mathrm{g} / \mathrm{mL}$ was chosen. The incubation with $200 \mu \mathrm{g} / \mathrm{mL}$ of piperine for $72 \mathrm{~h}$ led to death of all cells in wells; all lower piperine concentrations used were nontoxic to Vero cells (data not shown).

To determine the infectious activity of viral progeny, ten-fold dilutions of the supernatants collected from the experimental wells and viral controls in serum-free DMEM/F12 medium were prepared. The resulting dilutions were added to a 96-well culture plate with $80-90 \%$ Vero cell monolayer and incubated for $72 \mathrm{~h}$. After that, visual assessment of the cytopathogenic effect (CPE) of the virus was performed. The control samples without any additives demonstrated that the virus titer was $10^{4} \mathrm{TCID}_{50} / \mathrm{mL}$. Samples with a piperine concentration of $1.56 \mu \mathrm{g} / \mathrm{mL}$ resulted in $10^{3} \mathrm{TCID}_{50} / \mathrm{mL}$; alkaloid concentrations of $3.12-25 \mu \mathrm{g} / \mathrm{mL}$ had $10^{2} \mathrm{TCID}_{50} / \mathrm{mL}$, and in samples with piperine, concentrations of 50 and $100 \mu \mathrm{g} / \mathrm{mL}$ CPE were not observed at all. Thus, the significant reduction of the titer of SARS-CoV2 progeny in Vero cells at $1.56-100 \mu \mathrm{g} / \mathrm{mL}$ of piperine was clearly demonstrated.

\section{Conclusions}

New broad-spectrum antiviral drugs are needed due to the increase in the number of viral infections. Virus fusion inhibitors could be effective antiviral agents because fusion is a necessary step for the lifecycle of the virus. We used plant secondary metabolites, in particular, alkaloids, as a new class of fusion inhibitors. It was shown that the ability of alkaloids to inhibit calcium-mediated fusion of liposomes depends on their lipid composition. A correlation between the anti-fusogenic activity of alkaloids and their disordering effects on membrane lipids was found. Additionally, the ability of piperine to suppress the fusion induced by fragments of the coronavirus fusion peptides (MERS-CoV and SARS-CoV/SARS-CoV-2) was demonstrated. We also showed that piperine dramatically reduced the titer of SARS-CoV2 progeny in vitro in Vero cells when used in non-toxic concentrations. Thus, we hypothesize that the antiviral activity of piperine is related to its lipid-associated action. Moreover, to our knowledge, except for one bioassay with SARSCoV-2-S pseudotyped particles [72], this is the first study demonstrating the in vitro activity of piperine against SARS-CoV-2 virus. It should be noted that piperine with curcumin is being studied in several clinical trials for the treatment of COVID-19 [73-75]. According to [75], administration of oral curcumin with piperine substantially reduced the morbidity and mortality due to COVID-19. We hope that, over time, the number of effective alkaloids in the treatment of COVID-19 will increase. The use of plant metabolites can successfully complete the existing therapeutic strategies, which will make it possible to combat the SARS-CoV-2 virus more effectively.

Supplementary Materials: The following are available online at https://www.mdpi.com/article/10 .3390 / biomedicines9101434/s1, Figure S1: The chemical structures of the tested alkaloids, Figure S2: The time dependence of relative fluorescence of calcein leaked from DOPG/CHOL (80/20 mol\%) (a), DOPC/DOPG/CHOL (40/40/20 mol\%) (b), and POPC/SM/CHOL (60/20/20 mol\%) (c,d) vesicles induced by different concentrations of $\mathrm{CaCl}_{2}(\mathrm{a}, \mathrm{b})$, FP-SARS-CoV-2 (c) and FP-MERS-CoV (d). The relationship between the color line and the concentration of the fusion inducers is given in the figure; Figure S3: The time dependence of relative fluorescence of calcein $\left(R F_{A}, \%\right)$ leaked from DOPG/CHOL (80/20 mol\%) (a), DOPC/DOPG/CHOL (40/40/20 mol\%) (b), and POPC/SM/CHOL $(60 / 20 / 20 \mathrm{~mol} \%)$ (c) vesicles induced by alkaloids alone. Alkaloids were added into the liposomal suspension up to a concentration of $400 \mu \mathrm{M}$ (except for $40 \mu \mathrm{M}$ of tabersonine in DOPG/CHOL and DOPC/DOPG/CHOL vesicles) at the initial moment. The relationship between the color line and the compound is given in the figure; Figure S4. The time dependence of relative fluorescence of 
calcein $\left(R F_{S}, \%\right)$ leaked by the fusion of DOPG/CHOL ( $80 / 20 \mathrm{~mol} \%$ ) (a-c) and DOPC/DOPG/CHOL $(40 / 40 / 20 \mathrm{~mol} \%)\left(\mathrm{d}-\mathrm{f}\right.$ ) vesicles induced by $20 \mathrm{mM}$ of $\mathrm{CaCl}_{2}$ in the absence (black line) and presence of alkaloids. Liposomes were incubated with $400 \mu \mathrm{M}$ of alkaloids (except for $40 \mu \mathrm{M}$ of tabersonine) for $30 \mathrm{~min}$ before the addition of $\mathrm{CaCl}_{2}$. The relationship between the color line and the alkaloid is given in the figure; Figure S5: The dependence of the changes in the membrane boundary potential $\left(\Delta \varphi_{b}\right)$ on the concentration of colchicine $(*)$, cotinine $(\mathbf{\Lambda})$, 1,7-dimethylxanthine $(\boldsymbol{\square})$, capsaicin $(\bigcirc)$, synephrine $(\diamond)$, 3-isobutyl-1-methylxanthine $(\bullet)$, lupinine $(\square)$, piperine $(\boldsymbol{\nabla})$, tabersonine $(\diamond)$, and hordenine $(\bullet)$. The membranes were composed of DOPG/CHOL $(80 / 20 \mathrm{~mol} \%)$ and bathed in $0.1 \mathrm{M} \mathrm{KCl}$ at $\mathrm{pH}$ 7.4. $V=50 \mathrm{mV}$, Figure S6: The $\zeta$-potential of the POPC/SM/CHOL (60/20/20 mol\%) liposomes before and after addition of $50 \mu \mathrm{M}$ of FP-SARS-CoV-2 or $200 \mu \mathrm{M}$ of FP-MERS-CoV to unmodified and pretreated by $400 \mu \mathrm{M}$ of piperine vesicles; Table S1: The parameters characterized the alkaloid molecules and their influence on the calcein leakage from liposomes of different composition.

Author Contributions: E.V.S.-investigation, analysis, validation, and writing (original draft); S.S.E.-investigation, analysis, and validation; N.M.Y.-investigation, A.A.M.-investigation, V.V.Z.investigation, A.V.S.-investigation, analysis, and writing (review draft), O.S.O.—conceptualization, project administration, supervision, analysis, and writing (original draft, review and editing). All authors have read and agreed to the published version of the manuscript.

Funding: This research was financially supported by the joint-stock company Evalar.

Conflicts of Interest: The authors declare that the research was conducted in the absence of any commercial or financial relationships that could be construed as a potential conflict of interest.

\section{References}

1. Patridge, E.; Gareiss, P.; Kinch, M.S.; Hoyer, D. An analysis of FDA-approved drugs: Natural products and their derivatives. Drug Discov. Today 2016, 21, 204-207. [CrossRef] [PubMed]

2. Zhao, J.; Shan, T.; Mou, Y.; Zhou, L. Plant-derived bioactive compounds produced by endophytic fungi. Mini Rev. Med. Chem. 2011, 11, 159-168. [CrossRef] [PubMed]

3. Mani, J.S.; Johnson, J.B.; Steel, J.C.; Broszczak, D.A.; Neilsen, P.M.; Walsh, K.B.; Naiker, M. Natural product-derived phytochemicals as potential agents against coronaviruses: A review. Virus Res. 2020, 284, 197989. [CrossRef]

4. Ngwa, W.; Kumar, R.; Thompson, D.; Lyerly, W.; Moore, R.; Reid, T.E.; Lowe, H.; Toyang, N. Potential of flavonoid-inspired phytomedicines against COVID-19. Molecules 2020, 25, 2707. [CrossRef]

5. Kishimoto, S.; Sato, M.; Tsunematsu, Y.; Watanabe, K. Evaluation of biosynthetic pathway and engineered biosynthesis of alkaloids. Molecules 2016, 21, 1078. [CrossRef]

6. Xu, W.; Zhang, M.; Liu, H.; Wei, K.; He, M.; Li, X.; Hu, D.; Yang, S.; Zheng, Y. Antiviral activity of aconite alkaloids from Aconitum carmichaelii Debx. Nat. Rrod. Res. 2019, 33, 1486-1490. [CrossRef]

7. Cushnie, T.P.; Cushnie, B.; Lamb, A.J. Alkaloids: An overview of their antibacterial, antibiotic-enhancing and antivirulence activities. Int. J. Antimicrob. Agents 2014, 44, 377-386. [CrossRef]

8. Khan, H.; Mubarak, M.S.; Amin, S. Antifungal potential of alkaloids as an emerging therapeutic target. Curr. Drug Targets 2017, 18, 1825-1835. [CrossRef]

9. Boyd, M.R.; Hallock, Y.F.; Cardellina, J.H., 2nd; Manfredi, K.P.; Blunt, J.W.; McMahon, J.B.; Buckheit, R.W., Jr.; Bringmann, G.; Schäffer, M.; Cragg, G.M. Anti-HIV michellamines from Ancistrocladus korupensis. J. Med. Chem. 1994, 37, 1740-1745. [CrossRef]

10. Houghton, P.J.; Woldemariam, T.Z.; Khan, A.I.; Burke, A.; Mahmood, N. Antiviral activity of natural and semi-synthetic chromone alkaloids. Antivir. Res. 1994, 25, 235-244. [CrossRef]

11. Bodiwala, H.S.; Sabde, S.; Mitra, D.; Bhutani, K.K.; Singh, I.P. Synthesis of 9-substituted derivatives of berberine as anti-HIV agents. Eur. J. Med. Chem. 2011, 46, 1045-1049. [CrossRef]

12. Wan, Z.; Lu, Y.; Liao, Q.; Wu, Y.; Chen, X. Fangchinoline inhibits human immunodeficiency virus type 1 replication by interfering with gp160 proteolytic processing. PLoS ONE 2012, 7, e39225. [CrossRef]

13. Varghese, F.S.; Kaukinen, P.; Gläsker, S.; Bespalov, M.; Hanski, L.; Wennerberg, K.; Kümmerer, B.M.; Ahola, T. Discovery of berberine, abamectin and ivermectin as antivirals against chikungunya and other alphaviruses. Antivir. Res. 2016, 126, 117-124. [CrossRef]

14. Liu, X.; Wang, Y.; Zhang, M.; Li, G.; Cen, Y. Study on the inhibitory effect of cepharanthine on herpes simplex type-1 virus (HSV-1) in vitro. Zhong Yao Cai 2004, 27, 107-110. [PubMed]

15. Chin, L.W.; Cheng, Y.W.; Lin, S.S.; Lai, Y.Y.; Lin, L.Y.; Chou, M.Y.; Chou, M.C.; Yang, C.C. Anti-herpes simplex virus effects of berberine from Coptidis rhizoma, a major component of a Chinese herbal medicine, Ching-Wei-San. Arch. Virol. 2010, 155, 1933-1941. [CrossRef] [PubMed]

16. Liou, J.T.; Chen, Z.Y.; Ho, L.J.; Yang, S.P.; Chang, D.M.; Liang, C.C.; Lai, J.H. Differential effects of triptolide and tetrandrine on activation of COX-2, NF-kappaB, and AP-1 and virus production in dengue virus-infected human lung cells. Eur. J. Pharmacol. 2008, 589, 288-298. [CrossRef] 
17. Hung, T.C.; Jassey, A.; Liu, C.H.; Lin, C.J.; Lin, C.C.; Wong, S.H.; Wang, J.Y.; Yen, M.H.; Lin, L.T. Berberine inhibits hepatitis C virus entry by targeting the viral E2 glycoprotein. Phytomedicine 2019, 53, 62-69. [CrossRef]

18. Gao, Y.; Tai, W.; Wang, N.; Li, X.; Jiang, S.; Debnath, A.K.; Du, L.; Chen, S. Identification of novel natural products as effective and broad-spectrum anti-zika virus inhibitors. Viruses 2019, 11, 1019. [CrossRef]

19. Warowicka, A.; Nawrot, R.; Goździcka-Józefiak, A. Antiviral activity of berberine. Arch. Virol. 2020, 165, 1935-1945. [CrossRef]

20. Sakurai, Y.; Kolokoltsov, A.A.; Chen, C.C.; Tidwell, M.W.; Bauta, W.E.; Klugbauer, N.; Grimm, C.; Wahl-Schott, C.; Biel, M.; Davey, R.A. Ebola virus. Two-pore channels control Ebola virus host cell entry and are drug targets for disease treatment. Science 2015, 347, 995-998. [CrossRef]

21. Dang, Z.; Jung, K.; Zhu, L.; Lai, W.; Xie, H.; Lee, K.H.; Huang, L.; Chen, C.H. Identification and synthesis of quinolizidines with anti-influenza a virus activity. ACS Med. Chem. Lett. 2014, 5, 942-946. [CrossRef]

22. Dai, J.P.; Wang, Q.W.; Su, Y.; Gu, L.M.; Deng, H.X.; Chen, X.X.; Li, W.Z.; Li, K.S. Oxymatrine inhibits influenza a virus replication and inflammation via TLR4, p38 MAPK and NF-кB pathways. Int. J. Mol. Sci. 2018, 19, 965. [CrossRef]

23. Li, S.Y.; Chen, C.; Zhang, H.Q.; Guo, H.Y.; Wang, H.; Wang, L.; Zhang, X.; Hua, S.N.; Yu, J.; Xiao, P.G.; et al. Identification of natural compounds with antiviral activities against SARS-associated coronavirus. Antivir. Res. 2005, 67, 18-23. [CrossRef] [PubMed]

24. Kim, H.Y.; Shin, H.S.; Park, H.; Kim, Y.C.; Yun, Y.G.; Park, S.; Shin, H.J.; Kim, K. In vitro inhibition of coronavirus replications by the traditionally used medicinal herbal extracts, Cimicifuga rhizoma, Meliae cortex, Coptidis rhizoma, and Phellodendron cortex. J. Clin. Virol. 2008, 41, 122-128. [CrossRef] [PubMed]

25. Kim, D.E.; Min, J.S.; Jang, M.S.; Lee, J.Y.; Shin, Y.S.; Song, J.H.; Kim, H.R.; Kim, S.; Jin, Y.H.; Kwon, S. Natural bis-benzylisoquinoline alkaloids-tetrandrine, fangchinoline, and cepharanthine, inhibit human coronavirus OC43 infection of MRC-5 human lung cells. Biomolecules 2019, 9, 696. [CrossRef]

26. Fielding, B.C.; da Silva Maia Bezerra Filho, C.; Ismail, N.; Sousa, D.P. Alkaloids: Therapeutic potential against human coronaviruses. Molecules 2020, 25, 5496. [CrossRef] [PubMed]

27. Wu, R.; Wang, L.; Kuo, H.D.; Shannar, A.; Peter, R.; Chou, P.J.; Li, S.; Hudlikar, R.; Liu, X.; Liu, Z.; et al. An update on current therapeutic drugs treating COVID-19. Curr. Pharmacol. Rep. 2020, 11, 1-15. [CrossRef] [PubMed]

28. Della-Torre, E.; Della-Torre, F.; Kusanovic, M.; Scotti, R.; Ramirez, G.A.; Dagna, L.; Tresoldi, M. Treating COVID-19 with colchicine in community healthcare setting. Clin. Immunol. 2020, 217, 108490. [CrossRef]

29. Tan, G.T.; Pezzuto, J.M.; Kinghorn, A.D.; Hughes, S.H. Evaluation of natural products as inhibitors of human immunodeficiency virus type 1 (HIV-1) reverse transcriptase. J. Nat. Prod. 1991, 54, 143-154. [CrossRef]

30. Kim, S.Y.; Kim, H.; Kim, S.W.; Lee, N.R.; Yi, C.M.; Heo, J.; Kim, B.J.; Kim, N.J.; Inn, K.S. An effective antiviral approach targeting hepatitis B virus with NJK14047, a novel and selective biphenyl amide p38 mitogen-activated protein kinase inhibitor. Antimicrob. Agents Chemother. 2017, 61, e00214-e00217. [CrossRef]

31. Rey, F.A.; Lok, S.M. Common features of enveloped viruses and implications for immunogen design for next-generation vaccines. Cell 2018, 172, 1319-1334. [CrossRef]

32. Vigant, F.; Santos, N.C.; Lee, B. Broad-spectrum antivirals against viral fusion. Nat. Rev. Microbiol. 2015, 13, 426-437. [CrossRef]

33. Rout, J.; Swain, B.C.; Tripathy, U. In silico investigation of spice molecules as potent inhibitor of SARS-CoV-2. J. Biomol. Struct. Dyn. 2020, 1-15. [CrossRef]

34. Junior, A.G.; Tolouei, S.; Dos Reis Lívero, F.A.; Gasparotto, F.; Boeing, T.; de Souza, P. Natural agents modulating ACE-2: A review of compounds with potential against SARS-CoV-2 infections. Curr. Pharm. Des. 2021, 27, 1588-1596. [CrossRef]

35. Lv, X.Q.; Zou, L.L.; Tan, J.L.; Li, H.; Li, J.R.; Liu, N.N.; Dong, B.; Song, D.Q.; Peng, Z.G. Aloperine inhibits hepatitis C virus entry into cells by disturbing internalisation from endocytosis to the membrane fusion process. Eur. J. Pharmacol. 2020, 883, 173323. [CrossRef]

36. Enkhtaivan, G.; Muthuraman, P.; Kim, D.H.; Mistry, B. Discovery of berberine based derivatives as anti-influenza agent through blocking of neuraminidase. Bioorg. Med. Chem. 2017, 25, 5185-5193. [CrossRef]

37. Buzón, V.; Cladera, J. Effect of cholesterol on the interaction of the HIV GP41 fusion peptide with model membranes. Importance of the membrane dipole potential. Biochemistry 2006, 45, 15768-15775. [CrossRef] [PubMed]

38. Barz, B.; Wong, T.C.; Kosztin, I. Membrane curvature and surface area per lipid affect the conformation and oligomeric state of HIV-1 fusion peptide: A combined FTIR and MD simulation study. Biochim. Biophys. Acta 2008, 1778, 945-953. [CrossRef]

39. Matsuda, K.; Hattori, S.; Komizu, Y.; Kariya, R.; Ueoka, R.; Okada, S. Cepharanthine inhibited HIV-1 cell-cell transmission and cell-free infection via modification of cell membrane fluidity. Bioorg. Med. Chem. Lett. 2014, 24, 2115-2117. [CrossRef] [PubMed]

40. Ashkenazi, A.; Viard, M.; Unger, L.; Blumenthal, R.; Shai, Y. Sphingopeptides: Dihydrosphingosine-based fusion inhibitors against wild-type and enfuvirtide-resistant HIV-1. FASEB J. 2012, 26, 4628-4636. [CrossRef] [PubMed]

41. Pattnaik, G.P.; Chakraborty, H. Coronin 1 derived tryptophan-aspartic acid containing peptides inhibit membrane fusion. Chem. Phys. Lipids 2018, 217, 35-42. [CrossRef]

42. Sardar, A.; Lahiri, A.; Kamble, M.; Mallick, A.I.; Tarafdar, P.K. Translation of mycobacterium survival strategy to develop a lipopeptide based fusion inhibitor. Angew. Chem. Int. Ed. Engl. 2021, 60, 6101-6106. [CrossRef]

43. Moreno, M.R.; Guillén, J.; Pérez-Berna, A.J.; Amorós, D.; Gómez, A.I.; Bernabeu, A.; Villalaín, J. Characterization of the interaction of two peptides from the $\mathrm{N}$ terminus of the NHR domain of HIV-1 gp41 with phospholipid membranes. Biochemistry 2007, 46, 10572-10584. [CrossRef] 
44. Franquelim, H.G.; Veiga, A.S.; Weissmüller, G.; Santos, N.C.; Castanho, M.A. Unravelling the molecular basis of the selectivity of the HIV-1 fusion inhibitor sifuvirtide towards phosphatidylcholine-rich rigid membranes. Biochim. Biophys. Acta 2010, 1798, 1234-1243. [CrossRef] [PubMed]

45. Kalvodova, L.; Sampaio, J.L.; Cordo, S.; Ejsing, C.S.; Shevchenko, A.; Simons, K. The lipidomes of vesicular stomatitis virus, semliki forest virus, and the host plasma membrane analyzed by quantitative shotgun mass spectrometry. J. Virol. 2009, 83, 7996-8003. [CrossRef]

46. Merz, A.; Long, G.; Hiet, M.S.; Brügger, B.; Chlanda, P.; Andre, P.; Wieland, F.; Krijnse-Locker, J.; Bartenschlager, R. Biochemical and morphological properties of hepatitis $C$ virus particles and determination of their lipidome. J. Biol. Chem. 2011, 286, 3018-3032. [CrossRef]

47. Gerl, M.J.; Sampaio, J.L.; Urban, S.; Kalvodova, L.; Verbavatz, J.M.; Binnington, B.; Lindemann, D.; Lingwood, C.A.; Shevchenko, A.; Schroeder, C.; et al. Quantitative analysis of the lipidomes of the influenza virus envelope and MDCK cell apical membrane. J. Cell Biol. 2012, 196, 213-221. [CrossRef]

48. Chicka, M.C.; Hui, E.; Liu, H.; Chapman, E.R. Synaptotagmin arrests the SNARE complex before triggering fast, efficient membrane fusion in response to $\mathrm{Ca}^{2+}$. Nat. Struct. Mol. Biol. 2008, 15, 827-835. [CrossRef]

49. Lai, A.L.; Millet, J.K.; Daniel, S.; Freed, J.H.; Whittaker, G.R. The SARS-CoV fusion peptide forms an extended bipartite fusion platform that perturbs membrane order in a calcium-dependent manner. J. Mol. Biol. 2017, 429, 3875-3892. [CrossRef]

50. Yang, Q.; Guo, Y.; Li, L.; Hui, S.W. Effects of lipid headgroup and packing stress on poly(ethylene glycol)-induced phospholipid vesicle aggregation and fusion. Biophys. J. 1997, 73, 277-282. [CrossRef]

51. Lentz, B.R. PEG as a tool to gain insight into membrane fusion. Eur. Biophys. J. 2007, 36, 315-326. [CrossRef]

52. Khelashvili, G.; Plante, A.; Doktorova, M.; Weinstein, H. $\mathrm{Ca}^{2+}$-dependent mechanism of membrane insertion and destabilization by the SARS-CoV-2 fusion peptide. Biophys. J. 2021, 120, 1105-1119. [CrossRef]

53. Montal, M.; Muller, P. Formation of bimolecular membranes from lipid monolayers and study of their electrical properties. Proc. Nat. Acad. Sci. USA 1972, 65, 3561-3566. [CrossRef] [PubMed]

54. Andersen, O.S.; Finkelstein, A.; Katz, I.; Cass, A. Effect of phloretin on the permeability of thin lipid membranes. J. Gen. Physiol. 1976, 67, 749-771. [CrossRef] [PubMed]

55. Folli, C.; Calderone, V.; Ottonello, S.; Bolchi, A.; Zanotti, G.; Stoppini, M.; Berni, R. Identification, retinoid binding, and x-ray analysis of a human retinol-binding protein. Proc. Natl. Acad. Sci. USA 2001, 98, 3710-3715. [CrossRef] [PubMed]

56. Martín-Acebes, M.A.; Merino-Ramos, T.; Blázquez, A.B.; Casas, J.; Escribano-Romero, E.; Sobrino, F.; Saiz, J.C. The composition of West Nile virus lipid envelope unveils a role of sphingolipid metabolism in flavivirus biogenesis. J. Virol. 2014, 88, 12041-12054 [CrossRef] [PubMed]

57. Akimov, S.A.; Molotkovsky, R.J.; Kuzmin, P.I.; Galimzyanov, T.R.; Batishchev, O.V. Continuum models of membrane fusion: Evolution of the theory. Int. J. Mol. Sci. 2020, 21, 3875. [CrossRef]

58. Ketter, E.; Randall, G. Virus impact on lipids and membranes. Annu. Rew. Virol. 2019, 6, 319-340. [CrossRef]

59. de Lima, V.R.; Caro, M.S.; Munford, M.L.; Desbat, B.; Dufourc, E.; Pasa, A.A.; Creczynski-Pasa, T.B. Influence of melatonin on the order of phosphatidylcholine-based membranes. J. Pineal Res. 2010, 49, 169-175. [CrossRef]

60. Torrecillas, A.; Schneider, M.; Fernández-Martínez, A.M.; Ausili, A.; de Godos, A.M.; Corbalán-García, S.; Gómez-Fernández, J.C. Capsaicin fluidifies the membrane and localizes itself near the lipid-water interface. ACS Chem. Neurosci. 2015, 6, 1741-1750. [CrossRef]

61. Lebecque, S.; Crowet, J.M.; Lins, L.; Delory, B.M.; du Jardin, P.; Fauconnier, M.L.; Deleu, M. Interaction between the barley allelochemical compounds gramine and hordenine and artificial lipid bilayers mimicking the plant plasma membrane. Sci. Rep. 2018, 8, 9784. [CrossRef]

62. Ashrafuzzaman, M. Amphiphiles capsaicin and triton X-100 regulate the chemotherapy drug colchicine's membrane adsorption and ion pore formation potency. Saudi J. Biol. Sci. 2021, 28, 3100-3109. [CrossRef] [PubMed]

63. Ashrafuzzaman, M.; Tseng, C.Y.; Duszyk, M.; Tuszynski, J.A. Chemotherapy drugs form ion pores in membranes due to physical interactions with lipids. Chem. Biol. Drug Des. 2012, 80, 992-1002. [CrossRef] [PubMed]

64. Pentak, D. In vitro spectroscopic study of piperine-encapsulated nanosize liposomes. Eur. Biophys. J. 2016, 45, 175-186. [CrossRef]

65. Zidovetzki, R.; Sherman, I.W.; Atiya, A.; De Boeck, H. A nuclear magnetic resonance study of the interactions of the antimalarials chloroquine, quinacrine, quinine and mefloquine with dipalmitoylphosphatidylcholine bilayers. Mol. Biochem. Parasitol. 1989, 35, 199-207. [CrossRef]

66. Swain, J.; Kumar Mishra, A. Location, partitioning behavior, and interaction of capsaicin with lipid bilayer membrane: Study using its intrinsic fluorescence. J. Phys. Chem. B 2015, 119, 12086-12093. [CrossRef]

67. Efimova, S.S.; Zakharova, A.A.; Ostroumova, O.S. Alkaloids modulate the functioning of ion channels produced by antimicrobial agents via an influence on the lipid host. Front. Cell Dev. Biol. 2020, 8, 537. [CrossRef]

68. Taylor, K.M.; Morris, R.M. Thermal analysis of phase transition behaviour in liposomes. Thermochim. Acta. 1995, $248,289-301$. [CrossRef]

69. McElhaney, R.N. The use of differential scanning calorimetry and differential thermal analysis in studies of model and biological membranes. Chem. Phys. Lipids 1982, 30, 229-259. [CrossRef] 
70. Zakaria, M.Y.; Fayad, E.; Althobaiti, F.; Zaki, I.; Abu Almaaty, A.H. Statistical optimization of bile salt deployed nanovesicles as a potential platform for oral delivery of piperine: Accentuated antiviral and anti-inflammatory activity in MERS-CoV challenged mice. Drug Deliv. 2021, 28, 1150-1165. [CrossRef]

71. Hegeto, L.A.; Caleffi-Ferracioli, K.R.; Nakamura-Vasconcelos, S.S.; Almeida, A.L.; Baldin, V.P.; Nakamura, C.V.; Siqueira, V.L.D.; Scodro, R.B.L.; Cardoso, R.F. In vitro combinatory activity of piperine and anti-tuberculosis drugs in Mycobacterium tuberculosis. Tuberculosis (Edinb.) 2018, 111, 35-40. [CrossRef] [PubMed]

72. Primary qHTS to Identify Inhibitors of SARS-CoV-2 Cell Entry. Available online: https:/ / pubchem.ncbi.nlm.nih.gov/bioassay/ 1645846 (accessed on 14 July 2021).

73. Miryan, M.; Bagherniya, M.; Sahebkar, A.; Soleimani, D.; Rouhani, M.H.; Iraj, B.; Askari, G. Effects of curcumin-piperine co-supplementation on clinical signs, duration, severity, and inflammatory factors in patients with COVID-19: A structured summary of a study protocol for a randomised controlled trial. Trials 2020, 21, 1027. [CrossRef]

74. Askari, G.; Alikiaii, B.; Soleimani, D.; Sahebkar, A.; Mirjalili, M.; Feizi, A.; Iraj, B.; Bagherniya, M. Effect of curcumin-pipeine supplementation on clinical status, mortality rate, oxidative stress, and inflammatory markers in critically ill ICU patients with COVID-19: A structured summary of a study protocol for a randomized controlled trial. Trials 2021, 22, 434. [CrossRef] [PubMed]

75. Pawar, K.S.; Mastud, R.N.; Pawar, S.K.; Pawar, S.S.; Bhoite, R.R.; Bhoite, R.R.; Kulkarni, M.V.; Deshpande, A.R. Oral curcumin with piperine as adjuvant therapy for the treatment of COVID-19: A randomized clinical trial. Front. Pharmacol. 2021, 12, 669362. [CrossRef] [PubMed] 